\title{
Celulose (Mangifera indica) modificada por melamina-sílica aplicada no tratamento de efluentes com precipitação quimicamente assistida
}

Cellulose (Mangifera indica) modified by melamine-silica applied in the treatment of effluents with chemically assisted precipitation

Celulosa (Mangifera indica) modificada por melamina-sílice aplicada en el tratamiento de efluentes con precipitación asistida químicamente

Jarbas Soares de Mesquita Junior ORCID: https://orcid.org/0000-0002-2750-7050 Universidade Federal do Piauí, Brasil E-mail: jarbasjunior.eng@gmail.com

Francisco Cardoso Figueiredo ORCID: https://orcid.org/0000-0003-2938-6480 Universidade Federal do Piauí, Brasil E-mail: fcfigueiredo19@hotmail.com Evânia Carvalho dos Santos ORCID: https://orcid.org/0000-0003-4992-0038 Universidade Federal do Piauí, Brasil E-mail: evaniacds2@gmail.com

Darlisson Slag Neri Silva ORCID: https://orcid.org/0000-0003-2896-0671 Universidade Federal do Piauí, Brasil E-mail: darlisson.ufpi@hotmail.com

José Ribeiro dos Santos Júnior ORCID: https://orcid.org/0000-0003-2197-2020 Universidade Federal do Piauí, Brasil E-mail: jribeiro@ufpi.edu.br

\begin{abstract}
Resumo
Este trabalho objetivou desenvolver um compósito a base de celulose, melamina e sílica. A celulose foi obtida dos resíduos de poda da Mangifera indica para o tratamento primário quimicamente assistido de efluentes da indústria têxtil. O compósito foi caracterizado por FT-IR, MEV, MET, TG-DTG e Potencial Zeta. O planejamento composto central foi aplicado para otimização da massa de compósito e tempo de contato na remoção de azul de metileno. $\mathrm{O}$ FT-IR mostrou que o compósito apresentou a banda para a melamina em $815 \mathrm{~cm}^{-1}$. O MEV e MET revelaram que na superfície do compósito há Nitrogênio da melamina, Silício e Sódio oriundos do catalisador. O TG-DTG mostrou que o compósito é termicamente mais estável que a celulose, com $65 \%$ de degradação. Pelo potencial zeta, valores de $\mathrm{pH}$ acima de 5 propiciam maior estabilização e incremento do caráter aniônico do compósito. Escolheu-se como a melhor condição para a aplicação $60 \mathrm{mg}$ de compósito e 30 minutos de tempo de contato, com remoção de $88,6 \pm 3,5 \%$ do azul de metileno. O estudo do $\mathrm{pH}$ revelou que acima de 5 , o compósito é mais eficiente. O processo de adsorção do corante pelo material apresentou-se coerente ao modelo de Langmuir $\left(\mathrm{R}^{2}=0,9921\right)$. Assim, o compósito de celulosemelamina-sílica desenvolvido foi eficaz na remoção do corante azul de metileno, apresentando-se como um material de baixo custo, biodegradável e eficiente, com potencialidades para a aplicação no tratamento dos efluentes da indústria têxtil.
\end{abstract}

Palavras-chave: Mangifera indica; Celulose; CEPT; Azul de metileno; Adsorção.

\begin{abstract}
The present work aimed to develop a composite based on cellulose, melamine and silica. Cellulose was obtained from the pruning residues of Mangifera indica for the chemically assisted primary treatment of effluents from the textile industry. The composite was characterized by FT-IR, SEM, TEM, TGA-DTG and Zeta Potential. The central composite planning was applied to optimize the composite mass and contact time in removing methylene blue. FT-IR showed that the composite presented the band for melamine at $815 \mathrm{~cm}^{-1}$. SEM and TEM revealed that on the composite surface there is melamine nitrogen, silicon and sodium from the catalyst. TGA-DTG showed that the composite is thermally more stable than cellulose, with $65 \%$ degradation. Due to the zeta potential, $\mathrm{pH}$ values above 5 provide greater stabilization and increase the anionic character of the composite. It was chosen as the best condition for the application $60 \mathrm{mg}$ of composite and 30 minutes of contact time, with removal of $88.6 \pm 3.5 \%$ of the methylene
\end{abstract}


blue. The $\mathrm{pH}$ study revealed that above 5 , the composite is more efficient. The dye adsorption process by the material was consistent with the Langmuir model $\left(\mathrm{R}^{2}=0.9921\right)$. Thus, the cellulose-melamine-silica composite developed was effective in removing the methylene blue dye, presenting itself as a low-cost, biodegradable and efficient material, with potential for application in the treatment of effluents from the textile industry.

Keywords: Mangifera indica; Cellulose; CEPT; Methylene blue; Adsorption.

\section{Resumen}

Este trabajo tuvo como objetivo desarrollar un composite a base de celulosa, melamina y sílice. La celulosa se obtuvo de los residuos de poda de Mangifera indica para el tratamiento primario asistido químicamente de efluentes de la industria textil. El compuesto se caracterizó por FT-IR, MEV, MET, TG-DTG y Zeta Potential. Se aplicó la planificación central del compuesto para optimizar la masa del compuesto y el tiempo de contacto para eliminar el azul de metileno. FT-IR mostró que el composite presentaba la banda de melamina a $815 \mathrm{~cm}^{-1}$. SEM y MET revelaron que en la superficie compuesta hay nitrógeno de melamina, silicio y sodio del catalizador. TG-DTG demostró que el material compuesto es térmicamente más estable que la celulosa, con un $65 \%$ de degradación. Debido al potencial zeta, los valores de $\mathrm{pH}$ superiores a 5 proporcionan una mayor estabilización y aumentan el carácter aniónico del material compuesto. Se eligió como la mejor condición para la aplicación de $60 \mathrm{mg}$ de composite y 30 minutos de tiempo de contacto, con remoción del 88,6 $\pm 3,5 \%$ del azul de metileno. El estudio de pH reveló que por encima de 5, el compuesto es más eficiente. El proceso de adsorción del tinte por el material fue consistente con el modelo de Langmuir $\left(\mathrm{R}^{2}=0.9921\right)$. Así, el compuesto de celulosa-melamina-sílice desarrollado fue eficaz para eliminar el colorante azul de metileno, presentándose como un material de bajo costo, biodegradable y eficiente, con potencial de aplicación en el tratamiento de efluentes de la industria textil.

Palabras clave: Mangifera indica; Celulosa; CEPT; Azul de metileno; Adsorción.

\section{Introdução}

Com o acelerado crescimento industrial nas últimas décadas, os problemas ambientais tornaram-se cada vez mais críticos, principalmente quanto ao uso inconsciente dos recursos hídricos do planeta. Muitas atividades industriais, principalmente as têxteis, produzem águas contaminadas com corantes que, em sua maioria, são carcinogênicos ou tóxicos aos animais e que podem afetar de maneira negativa o meio ambiente aquático, contaminando peixes e plantas (Yu et al., 2021).

Frequentemente, há o despejo das águas residuais contaminadas de forma inadequada e sem o devido tratamento. Por ano, cerca de 700.000 toneladas de corantes são produzidas no mundo, onde entre 10 e $60 \%$ da massa é perdida durante o processo de fabricação (Başaran Kankılıç \& Metin, 2020a). Devido à estabilização pela estrutura aromática, esses corantes são dificilmente biodegradados o que torna necessário a aplicação de metodologias que possam removê-los do meio (Lyu et al., 2020a).

O tratamento de efluentes geralmente envolve lagoas de estabilização e processos de sedimentação, que podem ser quimicamente assistidos objetivando aumentar a coagulação e a floculação (Han et al., 2019). A escolha do processo de tratamento mais eficiente depende diretamente do tipo de substância contaminante a ser removida da concentração e o fluxo do efluente. O tratamento primário quimicamente assistido (CEPT ou CAPS) consiste na utilização de agentes químicos para acelerar o processo de sedimentação dos contaminantes, aumentando a eficiência do tratamento (Zeng et al., 2020).

Além disso, entre as vantagens do CEPT, está a redução do tamanho das unidades subsequentes, baixo custo para implantação, pois não é necessário a realização de modificações avançadas de infraestrutura. Para a remoção de corantes, os processos de CEPT que se baseiam no princípio da adsorção se destacam como uma técnica de separação com boa seletividade e de fácil operacionalização (AL-Hammadi et al., 2018a). Durante o processo de adsorção, os corantes dispersos no meio aquoso são capturados por um material sólido, diminuindo a sua biodisponibilidade, assim, posteriormente o material onde o corante que foi adsorvido pode ser removido (Wang et al., 2019).

Entre os estudos de adsorção de corantes, destaca-se o desenvolvimento de adsorventes a base de carvão ativado (Xiong et al., 2017), resina e gel (Li et al., 2016), grafeno (Saleh et al., 2017), óxidos metálicos (Keshk \& Hamdy, 2019; Q. Zhang et al., 2015) e compósitos (AL-Hammadi et al., 2018b; Shen et al., 2021). A procura por materiais ecologicamente amigáveis e de baixo custo que possam desempenhar o papel de adsorventes é objeto crescente de estudo. Os compósitos a 
base de celulose são uma opção interessante, por se tratar de um material polimérico natural e biodegradável em certas condições, e que pode ser obtido a partir de fontes alternativas de matérias-primas (Yu et al., 2021).

A celulose é largamente aplicada na formulação de fármacos, cosméticos, alimentos, produção de materiais isolantes e também no tratamento de efluentes, o que proporcionou o desenvolvimento de diversos estudos para obtenção e funcionalização (Dong et al., 2021). A celulose é considerada um excelente substituto aos polímeros sintéticos a base de petróleo, podendo ser extraída de diversas plantas e fibras, como por exemplo, o bagaço da cana-de-açúcar, sisal, palha de arroz e de pinheiros (Başaran Kankılıç \& Metin, 2020b).

Dentre os resíduos sólidos urbanos, destacam-se as podas, que são oriundos do manejo da arborização urbana para remoção de troncos, galhos, ramos, folhas, sementes e frutos. Em 2010, o Instituto Brasileiro de Geografia e Estatística (IBGE) estimou em 160 mil toneladas por dia a quantidade de resíduos sólidos urbanos gerados no Brasil. Os resíduos de poda das arvores são ricos em carbono, nitrogênio e celulose entre outros constituintes que são muitas vezes desperdiçados, com a destinação a lixões e aterros sanitários, disposição direta no campo ou queimados (Meira, 2010).

A Mangifera indica é uma arvore da família Anacardiaceae, nativa da Ásia e que foi muito difundida no Brasil por se tratar de uma planta frutífera. Seu fruto é a manga, que possui polpa suculenta, doce e saborosa. A Mangifera indica foi disseminada pelo Brasil, podendo ser encontrada tanto em pomares para obtenção do fruto quanto na ornamentação das ruas e das casas brasileiras (Ameen et al., 2019a; Vieira et al., 2012). Por serem extremamente lenhosas, as podas da Mangifera indica geram um resíduo sólido que costuma ser descartado, muitas vezes sem nenhum aproveitamento (Gupta \& Iqbal, 2005).

Estudos recentes trazem a Mangifera indica no foco de várias pesquisas, como a utilização dos resíduos da casca na catálise sustentável para a síntese de biodiesel em temperatura ambiente (Laskar et al., 2020). A utilização do extrato da flor na fitosíntese de nanopartícula de prata para atuação como biorredutor e bactericida de largo espectro (Ameen et al., 2019b). Na utilização de carvão ativo preparado a partir da sua biomassa impregnada com Fe para a remoção de melanoidina (Rizvi et al., 2020). Anteriormente a serragem da madeira foi testada para a remoção de Cr (VI) (Kapur \& Mondal, 2013) e a semente natural e acidificada foi estudada como biossorvente para a remoção do corante reativo Laranja Victazol 3R de soluções aquosas (Alencar et al., 2012). Todavia, não consta na literatura estudos que façam a aplicação da celulose para adsorção de azul de metileno.

O azul de metileno é um dos corantes mais aplicados na indústria. É um composto aromático, heterocíclico, quando sólido exibe a coloração verde escuro e quando em solução aquosa produz a cor azul. Entre suas aplicações, destacam-se a aplicação bacteriológica, como indicador ácido base e no campo da biologia como corante (Yu et al., 2021). Porém, na indústria do couro e tecidos o corante é mais utilizado. Quando ingerido em concentrações superiores a $7 \mathrm{mg} / \mathrm{kg}$, pode levar a complicações para a saúde, como dor abdominais, náuseas, vômitos, diarreia e pressão alta (Beh et al., 2020).

Diante o exposto, este trabalho visa o desenvolvimento de um compósito de baixo custo de celulose obtido a partir dos resíduos de poda da Mangifera indica para aplicação no tratamento primário quimicamente assistido de efluentes oriundos da indústria têxtil. O compósito obtido foi caracterizado por espectroscopia no infravermelho por transformada de Fourier (FTIR), microscópio eletrônico de varredura (MEV), microscopia eletrônica de transmissão (MET), análise termogravimétrica (TG-DTG) e potencial Zeta. A melhor condição para aplicação do compósito foi feita por Planejamento composto central para as variáveis: massa de compósito e tempo de contato.

\section{Procedimento Experimental}

\subsection{Reagentes e soluções}

As soluções foram preparadas em água deionizada de alta pureza (resistividade $18,2 \mathrm{M} \Omega \mathrm{cm}$ ) obtida em sistema deionizador (Purelab Option Q, ELGA). O NaOH, utilizado para o procedimento de mercerização, a melamina, o silicato de 
sódio, o formaldeído e o azul de metileno foram obtidos da Sigma Aldrich. $\mathrm{O} \mathrm{NH}_{4} \mathrm{OH}$ foi adquirido na Dinâmica e o ácido acético glacial da Chemco. Todos os reagentes utilizados eram de grau analítico.

\subsection{Amostra}

A matéria-prima utilizada para extração da celulose foi a madeira proveniente de podas da mangueira (Mangifera

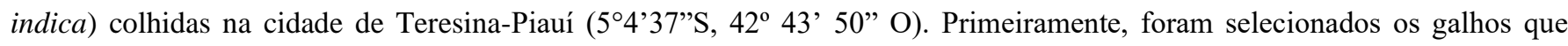
apresentavam aspecto saudável, sem a presença de fungos, parasitas ou ferimentos. A partir disso, com o auxílio de motosserra (STIHL, MS 661) os galhos mais externos foram serrados e a serragem oriunda da poda foi lavada e secada para remoção de impurezas. A amostra limpa foi pulverizada em almofariz e pistilo.

\subsection{Merceirização da celulose}

O procedimento de mercerização é um tratamento químico realizado com o intuito de remover a lignina e a hemicelulose da madeira e proporcionar o aumento da rugosidade superficial da fibra, e assim, favorecer a ancoragem mecânica da fibra pela matriz (Alila et al., 2013; El-kott et al., 2019). O processo de mercerização foi realizado de acordo com Marzouki et al. (2019), com pequenas modificações. Foi imersa em solução aquosa de 2,0 L de NaOH 20\% 500g de amostra. Desse modo, a mistura foi mantida sob agitação constante por 2 horas a $100{ }^{\circ} \mathrm{C}$. A reação foi interrompida com a adição de água deionizada em temperatura ambiente, após resfriada, a amostra foi lavada com água até pH 7. Por fim, a amostra neutra foi secada em estufa a $70{ }^{\circ} \mathrm{C}$ por 24 horas e armazenada em recipiente de polipropileno para as análises futuras.

\subsection{Síntese do compósito de celulose-melamina-sílica}

A preparação do compósito foi adaptada do método desenvolvido por Henriksson e Berglund (2007). Para tanto, a solução de melamina foi preparada pela dissolução de 2,0 $\mathrm{g}$ de melamina em $100 \mathrm{~mL}$ de água deionizada com adição de 3,0 $\mathrm{mL}$ de formaldeído $37 \%$, e mantida sob agitação constante a $60^{\circ} \mathrm{C}$. Em outro béquer, juntou-se 2,0 g de celulose; 2,0 mL de $\mathrm{NH}_{4} \mathrm{OH}$ concentrado e $4,7 \mathrm{~g}$ de silicato de sódio sob agitação de 40 minutos a $60^{\circ} \mathrm{C}$. Após esse período, a solução de melamina foi adicionada a solução de celulose e a correção do pH para 7 foi feita pela adição de ácido acético glacial, posteriormente, o sistema ficou em agitação por 30 minutos a $85^{\circ} \mathrm{C}$. A constatação da ocorrência da reação foi visual pela mudança de coloração da solução de marrom escuro para marrom claro, desse modo a solução foi filtrada, o compósito foi seco a $70{ }^{\circ} \mathrm{C}$ e pulverizado em almofariz e pistilo.

\subsection{Caracterização}

\subsubsection{Espectroscopia no infravermelho por transformada de Fourier (FT-IR)}

A espectroscopia na região do infravermelho com transformada de Fourier - FT-IR (Spectrum 400, PerkinElmer) foi feita com varredura entre 4000 e $400 \mathrm{~cm}^{-1}$ e resolução de $0,50 \mathrm{~cm}^{-1}$, utilizando pastilhas de $\mathrm{KBr}$.

\subsubsection{Microscópio eletrônico de varredura (MEV) e microscopia eletrônica de transmissão (MET)}

A morfologia foi realizada em microscópio eletrônico de varredura (MEV), no qual, as amostras foram polvilhadas em cima de fita dupla face condutora de carbono. Após isto, foram recobertas com material condutor ouro usando sistema para deposição de filmes de ouro (Desk V, Denton Vacuum LLC, Moorestown, New Jersey, USA), equipado com o acessório de carbono. Em seguida, as amostras foram analisadas no Microscópio Eletrônico de Varredura (MEV), JSM - 6610, Jeol, Tokyo, Japan, equipado com espectroscopia por energia dispersiva (EDS), Thermo scientific NSS Spectral Imaging. Para a microscopia eletrônica de transmissão (MET), as amostras foram dispersas em meio aquoso usando o limpador ultrassônico 
(Ultrasonic Branson 1510; Branson Ultrasonics Corp. Danbury, USA). Uma alíquota da amostra foi depositada na tela (grid) de cobre (especificações: grid de cobre recoberto com carbono de 400 mesh). Após a secagem as amostras foram analisadas no Microscópio Eletrônico de Transmissão (MET), JEM-2100, Jeol, Tokyo, Japan, equipado com EDS, Thermo scientific, operando em $200 \mathrm{kV}$.

\subsubsection{Analise termogravimétrica (TG-DTG)}

A análise termogravimétrica das amostras (TG-DTG) foi realizada no equipamento 60/60H (Shimadzu). Previamente, a amostra foi peneirada (200 mesh) e seca a $60^{\circ} \mathrm{C}$ por 10 minutos. As medidas foram feitas utilizando $10 \mathrm{mg}$ de amostra, em atmosfera de $\mathrm{N}_{2}$ com fluxo de $50 \mathrm{~mL} / \mathrm{min}$ e a taxa de aquecimento de $10{ }^{\circ} \mathrm{C} / \mathrm{min}$ até a temperatura máxima de $600{ }^{\circ} \mathrm{C}$.

\subsubsection{Potencial zeta}

As medidas para o potencial zeta (Nano particle analyzer, SZ-100 - HORIBA) do compósito foram realizadas de acordo com Shen et al. (2021), com ligeiras modificações. Para tanto, a concentração de compósito adicionado foi 0,5\% m/v, o pH da solução de $\mathrm{KCl}\left(0,01 \mathrm{~mol} \mathrm{~L}^{-1}\right)$ foi aferido com $\mathrm{HCl} 0,1 \mathrm{~mol} \mathrm{~L}^{-1}$ e $\mathrm{NaOH} 0,1 \mathrm{~mol} \mathrm{~L}^{-1}$ na faixa de 2 a 11 .

\subsection{Experimento de adsorção}

Para maximizar a eficiência de retenção do corante de azul de metileno (AM), foi realizada a otimização das variáveis tempo e massa de amostra. O planejamento composto central $2^{2}$, com ponto central mais quatro pontos axiais, é apresentado na Tabela 1. Para tanto, fez-se a codificação das duas variáveis e foi estabelecido o ponto central com seus respectivos pontos axiais, bem como a distribuição da quantidade de ensaios necessários para a realização do procedimento de otimização. Foram realizados 11 ensaios, com três réplicas no ponto central para estimar o erro associado. A análise do modelo e a significância estatística foram avaliadas e interpretadas por meio de superfície de resposta.

Tabela 1 - Variáveis e níveis para o planejamento composto central $2^{2}$ com ponto central mais pontos axiais.

\begin{tabular}{|c|c|c|c|c|c|c|}
\hline \multirow[b]{2}{*}{ Variáveis } & \multirow[b]{2}{*}{ Símbolo } & \multicolumn{5}{|c|}{ Níveis e Códigos } \\
\hline & & $-\sqrt{2}$ & -1 & 0 & +1 & $+\sqrt{2}$ \\
\hline Massa $(\mathrm{mg})$ & $\left(x_{1}\right)$ & 32 & 40 & 60 & 80 & 88 \\
\hline Tempo (min) & $\left(x_{2}\right)$ & 14 & 20 & 30 & 40 & 44 \\
\hline \multirow{2}{*}{ Ensaios } & \multicolumn{5}{|c|}{ Variáveis independentes } & \\
\hline & \multicolumn{2}{|c|}{$\operatorname{Massa}\left(x_{1}\right)$} & \multicolumn{4}{|c|}{ Tempo $\left(x_{2}\right)$} \\
\hline E1 & \multicolumn{2}{|c|}{-1} & \multicolumn{4}{|c|}{-1} \\
\hline E2 & \multicolumn{2}{|c|}{-1} & \multicolumn{4}{|c|}{+1} \\
\hline $\mathbf{E 3}$ & \multicolumn{2}{|c|}{+1} & \multicolumn{4}{|c|}{-1} \\
\hline E4 & \multicolumn{2}{|c|}{+1} & \multicolumn{4}{|c|}{+1} \\
\hline E5 & \multicolumn{2}{|c|}{$-\sqrt{2}$} & \multicolumn{4}{|c|}{0} \\
\hline E6 & \multicolumn{2}{|c|}{$+\sqrt{2}$} & \multicolumn{4}{|c|}{0} \\
\hline E7 & \multicolumn{2}{|c|}{0} & \multicolumn{4}{|c|}{$-\sqrt{2}$} \\
\hline E8 & \multicolumn{2}{|c|}{0} & \multicolumn{4}{|c|}{$+\sqrt{2}$} \\
\hline E9 & \multicolumn{2}{|c|}{0} & \multicolumn{4}{|c|}{0} \\
\hline E10 & \multicolumn{2}{|c|}{0} & \multicolumn{4}{|c|}{0} \\
\hline E11 & \multicolumn{2}{|c|}{0} & \multicolumn{4}{|c|}{0} \\
\hline
\end{tabular}

Fonte: Autores (2021).

\subsection{Ensaio de remoção do corante azul de metileno}

$\mathrm{O}$ estudo da capacidade de remoção de corante do compósito de celulose-melamina-sílica de Mangifera indica foi feito utilizando o azul de metileno. Inicialmente foi preparada uma solução estoque de $150 \mathrm{ppm}$ de azul de metileno em água. 
A partir da diluição da solução estoque foi obtido $100 \mathrm{~mL}$ para as concentrações de 1, 2, 3, 4 e 5 ppm. A melhor condição de aplicação do polímero foi aplicada em cada solução, a partir disso, o sistema foi centrifugado (Spinplus Titan, Daiki) a 4000 rpm por 5 minutos, ao fim do processo, o sobrenadante foi coletado e analisado em espectrofotômetro. A capacidade de adsorção do azul de metileno pelo compósito foi calculada da seguinte forma:

$$
\text { Capacidade de adsorção }(\%)=\left(\frac{c_{0}-c}{c_{0}}\right) \times 100 \quad \text { Equação } 1
$$

Nessa equação $C_{0}$ é a concentração inicial de azul de metileno e $C$ é a concentração registrada ao final do processo de adsorção. A quantificação do corante foi realizada em espectrofotômetro UV-Vis (Genesys 10S UV-Vis, Thermo Scientific) em $664 \mathrm{~nm}$. A construção de curva analítica foi feita a partir de diluições em série da solução estoque (150 ppm) para produzir a concentração variando de 1-5 ppm.

\subsection{Avaliação da influência do pH na adsorção de azul de metileno}

O estudo da influência do $\mathrm{pH}$ na remoção do corante foi feito na faixa de $\mathrm{pH}$ entre 2 a 11. Para tanto, foi preparada uma solução de azul de metileno 4 ppm, na qual a aferição do pH foi realizada com $\mathrm{HCl} 0,1 \mathrm{~mol} \mathrm{~L}^{-1} \mathrm{e} \mathrm{NaOH} 0,1 \mathrm{~mol} \mathrm{~L}^{-1}$. Posteriormente, foi adicionado $60 \mathrm{mg}$ de compósito a $100 \mathrm{~mL}$ de solução, a mistura foi agitada a $290 \mathrm{rpm}$ por 30 minutos, e a partir disso, centrifugada a 4000 rpm, o sobrenadante foi coletado e analisado em espectrofotômetro UV-Vis.

\subsection{Isoterma de adsorção}

O estudo da adequação do mecanismo de adsorção a isoterma de Langmuir foi realizado de acordo com Haque et al. (2020a), com algumas modificações. Com isso, utilizou-se $60 \mathrm{mg}$ de compósito, $100 \mathrm{~mL}$ de solução de azul de metileno nas concentrações $5,10,25,50,75,100,200,300,400$ e 500 ppm, no pH 6,2 da água deionizada. A mistura foi agitada por 30 minutos a $290 \mathrm{rpm}$, dessa forma foram centrifugadas a $4000 \mathrm{rpm}$ por 5 minutos. A adsorção foi determinada com base na concentração de corante antes e após a aplicação do compósito segundo a equação 2 :

$$
q_{e}=\frac{\mathrm{V}\left(C_{\mathrm{p}}-c_{\mathrm{g}}\right) \mathrm{W}}{m} \quad \text { Equação } 2
$$

Onde: $\mathrm{q}_{\mathrm{e}}=$ Capacidade de adsorção $\left(\mathrm{mg} \mathrm{g}^{-1}\right)$

$\mathrm{v}=$ Volume da solução $(\mathrm{L})$

$\mathrm{C}_{0}=$ concentração inicial da solução $\left(\mathrm{mg} \mathrm{L}^{-1}\right)$

$\mathrm{C}_{\mathrm{e}}=$ concentração em equilíbrio da solução $\left(\mathrm{mg} \mathrm{L}^{-1}\right)$

$m=$ massa do compósito $(\mathrm{g})$

\subsection{Análise estatística}

$\mathrm{O}$ tratamento estatístico dos experimentos e a interpretação dos dados foram realizados utilizando os softwares Statistica 12.5 e Origin 8.5. A análise de variância (ANOVA) foi realizada para determinar se há diferença significativa entre as médias obtidas. As análises foram feitas em triplicata e os resultados expressos em média mais desvio padrão. Todas as comparações foram realizadas com nível de confiança de $95 \%$ e a diferença significativa entre os valores médios foi avaliada pelo teste de Tukey. 


\section{Resultados e Discussão}

\subsection{Obtenção do compósito}

A síntese do compósito é apresentada na Figura 1, no qual foi utilizada a celulose mercerizada da Mangifera indica. A solução de celulose foi preparada pela adição de $\mathrm{NH}_{4} \mathrm{OH}$ concentrado juntamente com silicato de sódio, mantida sob agitação a $60{ }^{\circ} \mathrm{C}$ por 40 minutos. Diante disso, para a obtenção do compósito, foi feita a solução de melamina e formaldeído, que posteriormente foi adicionada a solução de celulose. A melamina é um núcleófilo que reage com até seis grupos de formaldeído para formar dois grupos de metilol em cada grupo amina exocíclica. Após a reação há a condensação para a formação da resina (Ullah et al., 2015a).

Figura 1 - Fluxograma de síntese do compósito celulose-melamina-sílica.
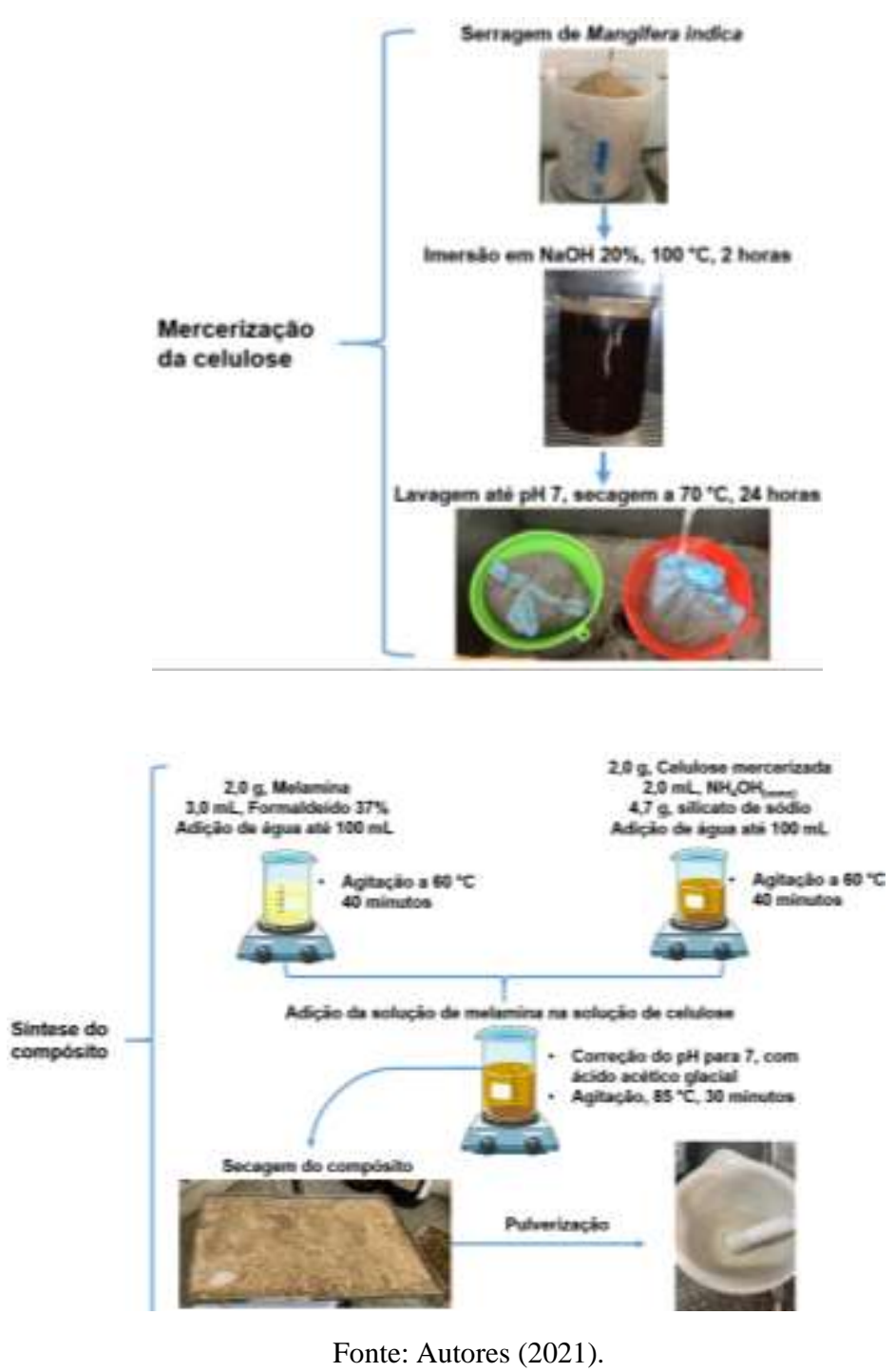

O silicato de sódio é muito utilizado na indústria de transformação de papel e na obtenção de adesivos (Merline et al., 2013). O silicato fornece ao material o incremento da rigidez e aumento do grau de aderência (Rehman \& Park, 2018). A aplicação do silicato de sódio permite a modificação química e a formação da hexametilolmelamina por meio da reação conhecida como organofuncionalização, dessa forma, tem-se uma área superficial maior que a da melamina (Lyu et al., 2020b; Sahiner et al., 2016; Seo et al., 2016a; Zhang \& Wang, 2009). Por ser rica em grupos hidroxila, a celulose reage com os grupos 
amino ou formaldeídos da hexametilolmelamina e permite a redução do tempo de condensação, pois as hidroxilas da celulose podem formar ligações covalentes com a resina melamina-sílica (Seo et al., 2016b).

\subsection{Caracterização}

\subsubsection{Espectroscopia no infravermelho por transformada de Fourier - FT-IR}

Os espectros de FT-IR da Figura 2 foram utilizados para observar a composição química e as mudanças que ocorreram durante o processo de síntese do compósito de celulose da Mangifera indica. A partir do espectro obtido para a celulose de Mangifera indica, a banda larga existente entre 3720 a $2980 \mathrm{~cm}^{-1}$ foi devido a vários modos vibracionais, dentre os quais estão: 3640 a $3620 \mathrm{~cm}^{-1}$, que correspondem as hidroxilas (OH) livres; e em aproximadamente $3560 \mathrm{~cm}^{-1}$, observou-se que a água é fracamente adsorvida na celulose; os estiramentos de O-H em 3645 a $3620 \mathrm{~cm}^{-1}$, também contribuem para a intensidade da banda, com destaque para o estiramento dos grupos $\mathrm{OH}$ que ocorrem intramolecularmente na região de 3570 a $3450 \mathrm{~cm}^{-1}$ e para a ligação intramolecular entre o $\mathrm{O}(2) \mathrm{H} . . . \mathrm{O}(6)$ na molécula de celulose que aparece por volta de 3455 a 3410 $\mathrm{cm}^{-1}$, entre 3310 e $3230 \mathrm{~cm}^{-1}$ ligação intramolecular O(6)H...O(3); 3400 a $3200 \mathrm{~cm}^{-1}$ de grupos O-H (Deeksha et al., 2021; Lutzke et al., 2020).

As bandas que surgem entre 3000 e $2800 \mathrm{~cm}^{-1}$ para a celulose equivalem ao estiramento $\mathrm{C}-\mathrm{H}$ dos grupos metílicos e metilênicos da celulose, nos quais 2984 a $2810 \mathrm{~cm}^{-1}$ remetem a vibração de valência assimétrica do grupo $\mathrm{CH}_{2}$ e $\mathrm{CH}_{2} \mathrm{OH}$ (C6); 2954 a $2877 \mathrm{~cm}^{-1}$ a vibração correspondente a valência simétrica do grupo $\mathrm{CH}_{2}$ e o estiramento que aparece entre 2877 - 2828 $\mathrm{cm}^{-1}$ do C-H sp ${ }^{3}$ da metoxila. Em $1630 \mathrm{~cm}^{-1}$, há a ocorrência da banda devido à presença de água adsorvida, entre 1689 e 1552 $\mathrm{cm}^{-1}$ há a presença do estiramento $\mathrm{C}=\mathrm{O}$.

Figura 2 - Espectro de FT-IR para a celulose, melamina e para o compósito.

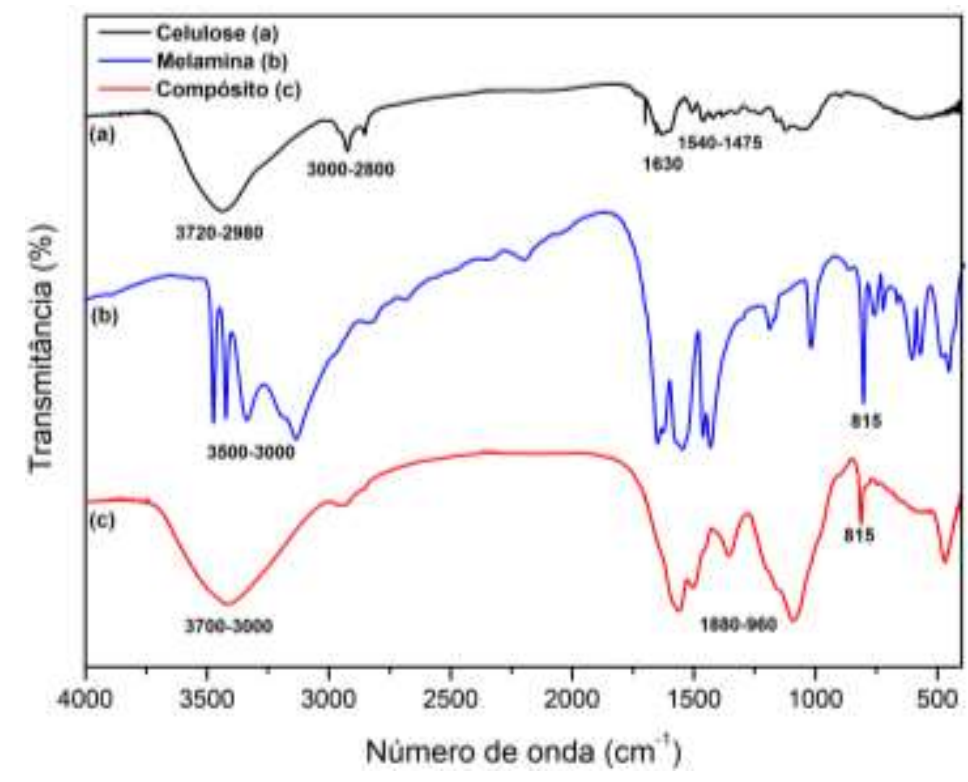

Fonte: Autores (2021).

As bandas entre 1540 a $1475 \mathrm{~cm}^{-1}$ correspondem à deformação de $\mathrm{CH}_{2}$ do anel pirano; $1465 \mathrm{~cm}^{-1}$ a deformação $\mathrm{C}-\mathrm{H}$ assimétrico dos grupos metoxila; $1431 \mathrm{~cm}^{-1}$ a deformação da ligação C-O-H; $1430 \mathrm{~cm}^{-1}$ a deformação C-O-H de álcoois no plano e entre 1430 a $1418 \mathrm{~cm}^{-1}$ a deformação do $\mathrm{CH}_{2}$ (Cai et al., 2019; Nagarajan et al., 2020). A banda $1386 \mathrm{~cm}^{-1}$ é característica de deformação C-H por vibração; 1348 a $1311 \mathrm{~cm}^{-1}$ deformação C-OH no plano; $1266 \mathrm{~cm}^{-1}$ deformação C-H; $1225 \mathrm{~cm}^{-1} \mathrm{C}-\mathrm{OH}$ no plano; $1159 \mathrm{~cm}^{-1} \mathrm{C}-\mathrm{OH}$ no plano; $1123 \mathrm{~cm}^{-1} \mathrm{C}-\mathrm{O}-\mathrm{C}$ vibração de valência assimétrica; entre 1089 a 1014 
$\mathrm{cm}^{-1}$ estiramentos C-C e C-O assimétricos do anel pirano; $1061 \mathrm{~cm}^{-1}$ deformação C-O em álcoois secundários. Em $1040 \mathrm{~cm}^{-1}$ ao estiramento C-O-C de éter alifático ( $\beta-1,4) ; 1060$ a $1015 \mathrm{~cm}^{-1}$ a vibração de valência da ligação $\mathrm{C}_{3}-\mathrm{O}_{3} \mathrm{H} ; 1076$ a $1004 \mathrm{~cm}^{-1}$ C-O-C a vibração de metoxila e da ligação $\beta-1,4$; na região de $998 \mathrm{~cm}^{-1}$ deformação C-O de álcoois primários e estiramento $\mathrm{C}=\mathrm{O}$ conjugado; 930 a $925 \mathrm{~cm}^{-1}$ vibrações do anel pirano; $897 \mathrm{~cm}^{-1}$ refere-se aos carbonos anoméricos e a deformação $\mathrm{C} 1-\mathrm{H}$; $715 \mathrm{~cm}^{-1}$ a deformação $\mathrm{CH}_{2} ; 664 \mathrm{~cm}^{-1}$ a deformação C-OH fora do plano (Chen et al., 2020).

Observando a região do espectro de FT-IR correspondente a 1730 e $1090 \mathrm{~cm}^{-1}$ para a celulose, verifica-se a baixa intensidade das bandas, que pode ser justificado pelo procedimento de mercerização que consistem em tratar a fibra vegetal com uma base forte, geralmente o $\mathrm{NaOH}$ a altas temperaturas para promover o rompimento das ligações de hidrogênio dos grupos hidroxila $(-\mathrm{OH})$ e possibilitar o aumento da rugosidade da superfície e remover alguns componentes da fibra vegetal como lignina, a hemicelulose e as ceras (Agwuncha et al., 2020a; Marzouki et al., 2019).

Após o tratamento das fibras de sisal com $\mathrm{NaOH} 2 \%(\mathrm{~m} / \mathrm{v})$, Singh et al. (2000) observou que houve a redução pronunciada das bandas de absorção na região de $1732 \mathrm{~cm}^{-1} \mathrm{e} 1714 \mathrm{~cm}^{-1}$ que é atribuído ao estiramento $\mathrm{C}=\mathrm{O}$ das carbonilas das pectinas presentes nas fibras naturais. A hemicelulose, polissacarídeos ramificados de massa molar inferior à celulose, costuma apresentar bandas de absorção em $1723 \mathrm{~cm}^{-1}$ dos grupos acetil. Uma vez realizado o processo de mercerização por tratamento alcalino, há a remoção de grande parte da hemicelulose presente nas fibras (Agwuncha et al., 2020b).

Portanto, por não ser possível constatar o aparecimento dessa banda de absorção na Figura 2 para a celulose, é possível inferir que o processo de tratamento da fibra foi satisfatório para a remoção da hemicelulose. Entre as principais bandas, estão a de absorção em $1734 \mathrm{~cm}^{-1}$ que corresponde ao estiramento $\mathrm{C}=\mathrm{O}$ dos grupos carboxílicos alifáticos ou de ésteres acrílicos, as bandas localizadas em $1653 \mathrm{~cm}^{-1}$ e $1507 \mathrm{~cm}^{-1}$ que são atribuídas ao estiramento das ligações $\mathrm{C}=\mathrm{C}$ dos anéis aromáticos em ligninas, e a banda em $1267 \mathrm{~cm}-1$ que remete a deformação do anel guaiacila do estiramento C-O (Agwuncha et al., 2020c; Gurgel et al., 2008; Júnior et al., 2009).

Marzouki et al. (2019), ao avaliar os efeitos da mercerização na estrutura e nas propriedades elétricas da celulose do algodão, constatou que a substituição do átomo de hidrogênio do grupo $\mathrm{OH}$ da celulose pelo íon de sódio na molécula $\mathrm{C}_{6} \mathrm{H}_{10} \mathrm{O}_{5} * \mathrm{NaOH}$ torna a ligação $\mathrm{C}-\mathrm{O}$ mais forte, pois há o direcionamento dos elétrons no sentido OH-NaOH, também ocorre o incremento na intensidade da banda do estiramento relativo ao $\mathrm{CH}_{2}$ que aparece entre 2954 a $2877 \mathrm{~cm}^{-1}$, também pode ser verificado que em $1050 \mathrm{~cm}^{-1}$ da celulose mercerizada há o aparecimento de uma banda larga que é atribuída ao estiramento assimétrico do anel da celulose.

No espectro de FT-IR para a melamina, apresentado na Figura 2, utilizada na síntese do compósito, observa-se as vibrações características para o estiramento dos grupos amino (N-H) que absorvem entre 3500 e $3000 \mathrm{~cm}^{-1}$. Bandas atribuídas as ligações de hidrogênio $(\mathrm{N}-\mathrm{H})$, entre $1700 \mathrm{e} 1330 \mathrm{~cm}^{-1}$ aparecem os picos relativos à flexão dos grupos amino. A presença da ligação de hidrogênio promove a diminuição no número de onda para a banda de estiramento entre o $\mathrm{N}$ e o $\mathrm{H}$ devido à ligação mais fraca. $\mathrm{O}$ pico forte observado em $3335 \mathrm{~cm}^{-1}$ pode ser atribuído ao estiramento assimétrico $\mathrm{NH}_{2}$, entretanto, o estiramento simétrico aparece em $3131 \mathrm{~cm}^{-1}$, e em $1656 \mathrm{~cm}^{-1}$ encontra-se a deformação do $\mathrm{NH}_{2} ; 1556 \mathrm{~cm}^{-1}$ há o estiramento do quadrante do anel 1,3,5-s-triazina; $1440 \mathrm{~cm}^{-1} \mathrm{o}$ estiramento do semicírculo do anel 1,3,5-s-triazina; $1438 \mathrm{~cm}^{-1}$ pertence ao estiramento C$\mathrm{N}$ da cadeia lateral; $1030 \mathrm{~cm}^{-1}$ é o estiramento $\mathrm{C}-\mathrm{N}$ de aminas primárias ligadas ao carbono primário (Marzouki et al., 2019). A banda característica para a melamina foi observada em $815 \mathrm{~cm}^{-1}$, relativa à curvatura fora do plano do anel 1,3,5-S-triazina (Chen et al., 2020; Hazarika et al., 2015). A determinação de melamina em leite em pó e leite líquido por FT-IR, Jawaid et al. (2014) aplica o método de Mínimos Quadrados Parciais (PLS) para correlacionar os dados coletados e as diferentes variáveis estudadas, na qual a melhor região para o estudo foi entre 851,62 e $798,39 \mathrm{~cm}^{-1}$, podendo ser justamente a faixa de aparecimento da banda característica da melamina referente ao anel 1,3,5-S-triazina. 
Para o compósito Mangifera indica, é notável a presença da banda larga resultante da associação polimérica, provavelmente oriunda da celulose entre 3700 e $3000 \mathrm{~cm}^{-1}$ devido aos modos vibracionais das hidroxilas que são mais intensos e sobrepõem os modos para o nitrogênio. Entre 1880 e $960 \mathrm{~cm}^{-1}$ há a presença de quatro bandas advindas da melamina, na qual $1557 \mathrm{~cm}^{-1}$ equivale ao estiramento do quadrante do anel 1,3,5-s-triazina; $1500 \mathrm{~cm}^{-1}$ o estiramento do semicírculo do anel; 1354 $\mathrm{cm}^{-1}$ equivale ao estiramento C-N da cadeia lateral e $1090 \mathrm{~cm}^{-1}$ é o estiramento $\mathrm{C}-\mathrm{N}$ de aminas primárias. Observou-se também a manutenção da banda característica para a melamina em $815 \mathrm{~cm}^{-1}$. Em aproximadamente $1090 \mathrm{~cm}^{-1}$ aparece o sinal referente a deformação axial do Si-O-Si, do silicato de sódio e em $466 \mathrm{~cm}^{-1}$ tem-se a deformação simétrica O-Si-O (Halasz et al., 2010).

Durante a síntese do compósito, a melamina foi posta em reação com o formaldeído. Primeiro tem-se a etapa da metiololação, na qual há a reação direta com a formação dos grupos metilol após a adição do formaldeído aos grupos de amina, em que a ligação N-H é feita com o grupo $\mathrm{C}=\mathrm{O}$ do formaldeído (Merline et al., 2013). Posteriormente, tem-se a etapa de condensação, que ocorre no carbono 6 da celulose e em várias etapas envolvendo a formação de compostos intermediários contendo ligação éter. A síntese do compósito, a partir dos compostos de metilol provenientes da primeira etapa por meio da reação de condensação, pode ocorrer com dois grupos metilol ou um grupo metilol e átomos de hidrogênio ativos. A reação é similar a utilizada na produção de resinas de ureia-formaldeído pela indústria de painéis aglomerado, todavia, a reação melamina-formaldeído é mais rápida e completa quando comparada com a ureia, e além disso, pode ocorrer em meio neutro e levemente básico (Ullah et al., 2015b).

\subsubsection{Caracterização morfológica}

\subsubsection{Microscopia eletrônica de varredura (MEV)}

Por meio da Microscopia Eletrônica de Varredura (MEV) foi possível investigar a estrutura morfológica de diversos compostos químicos. O MEV baseia-se na exploração da superfície da amostra pela interação existente entre os elétrons e a matéria (Kanemaru et al., 2010). O feixe de elétrons gerado é disparado em direção à amostra durante a análise, promovendo a varredura da superfície. Essa varredura ocorre sucessivamente de ponto a ponto da amostra e o sinal é transmitido a um detector, no qual é possível analisar as energias e a interação dos elétrons com a superfície da amostra. Esse sinal é interpretado pelo equipamento de gerar as imagens em alta definição (Gómez-Carracedo et al., 2009; Shen et al., 2021).

A micrografia para a celulose, Figura 3a, mostra que as fibras apresentam diferentes geometrias organizacionais. As dimensões dessas fibras formam uma espécie de tecido básico que dá forma a toda amostra. Na Figura 3b, observamos o topo das estruturas fibrosas no qual aparecem os elementos secretantes - cavidades verticais e radiais presentes em árvores lenhosas.

$\mathrm{Na}$ Figura 3c, o tecido da celulose apresenta-se bem definido. Esse tecido é resultante essencialmente das paredes celulares e apresenta estrutura relativamente simples e uniforme. Em face de sua composição básica nos tecidos da celulose, estão os traqueóides, cuja função é conduzir seiva bruta, que são observados como células alongadas e de pequena espessura, com orientação longitudinal na direção do eixo axial do tronco que em árvores adultas podem atingir $45 \mu \mathrm{m}$ de diâmetro e comprimento de cerca de $430 \mathrm{~nm}$ (Husson et al., 2011; Zimmermann et al., 2010).

As fibras das madeiras lenhosas são um conjunto de células aglomeradas pela lamela intercelular compostas em sua maioria por celulose, hemicelulose e lignina (Zhao et al., 2007). Ainda na Figura 3c, as células apresentam elevada uniformização e rugosidade, e, além disso, sua superfície se apresenta isenta de sustâncias cerosas. Isso é provavelmente resultado do processo de mercerização com $\mathrm{NaOH}$ (Kabir et al., 2012). Constatações similares foram feitas por Bogolitsyn et al. (2015) em fibras de madeira de juníperos e em sisal, e fibras de linho por Sreekala \& Thomas (2003). 
Figura 3 - Microscopia eletrônica de varredura para a celulose de Mangifera indica: a) - $500 \mu \mathrm{m}, \mathrm{x} 50$; b) - $100 \mu \mathrm{m}, \mathrm{x} 250$; c) $100 \mu \mathrm{m}, \mathrm{x} 200 ; \mathrm{d})-10 \mu \mathrm{m}, \mathrm{x} 2000$

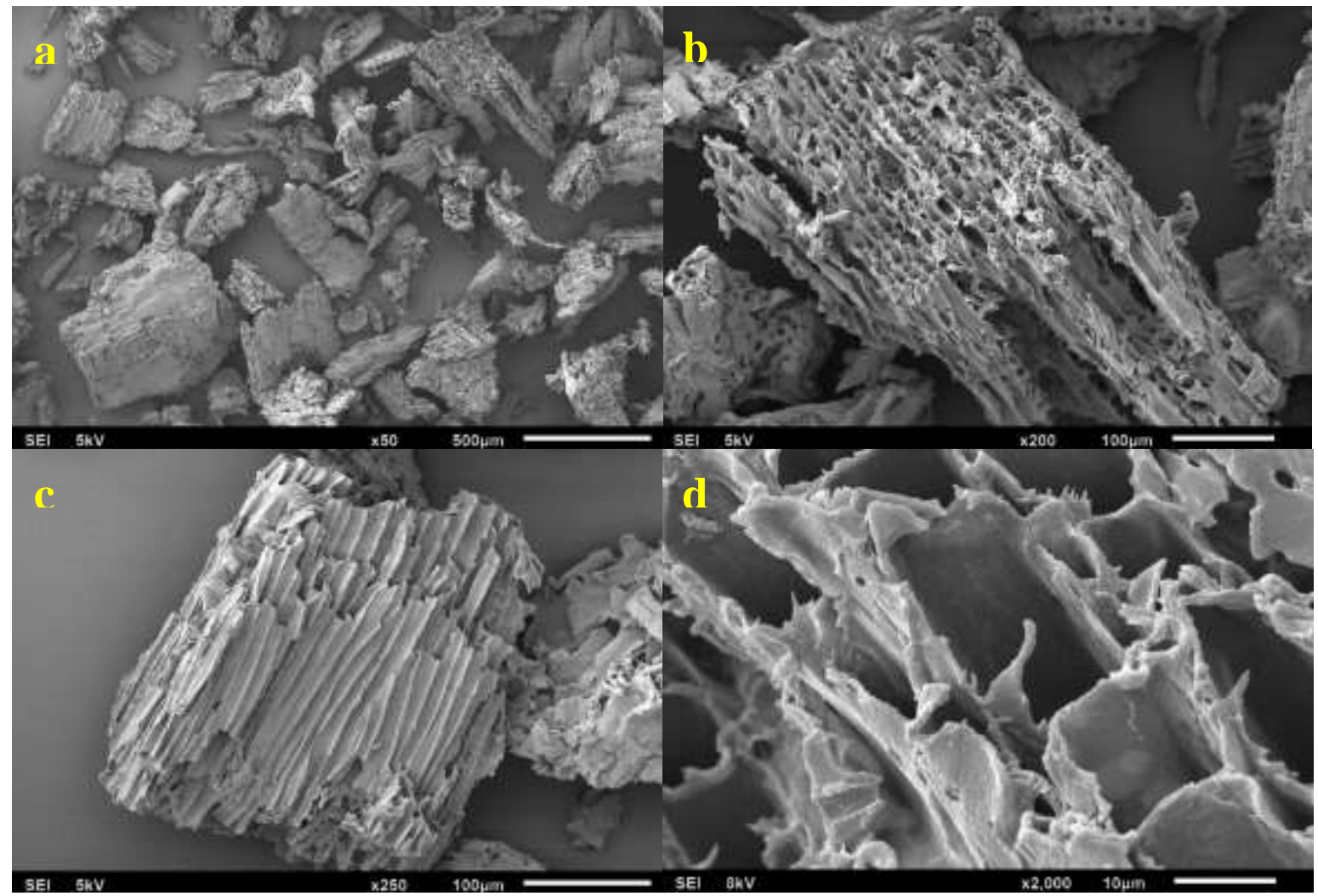

Fonte: Autores (2021). 
Figura 4 - Microscopia eletrônica de varredura para o compósito celulose-melamina-sílica, a) - $50 \mu \mathrm{m}$, x300; b) - 10 $\mu \mathrm{m}$, x2000; c) $-10 \mu \mathrm{m}, \mathrm{x} 2000 ;$ d) $-5 \mu \mathrm{m}, \mathrm{x} 5000$.

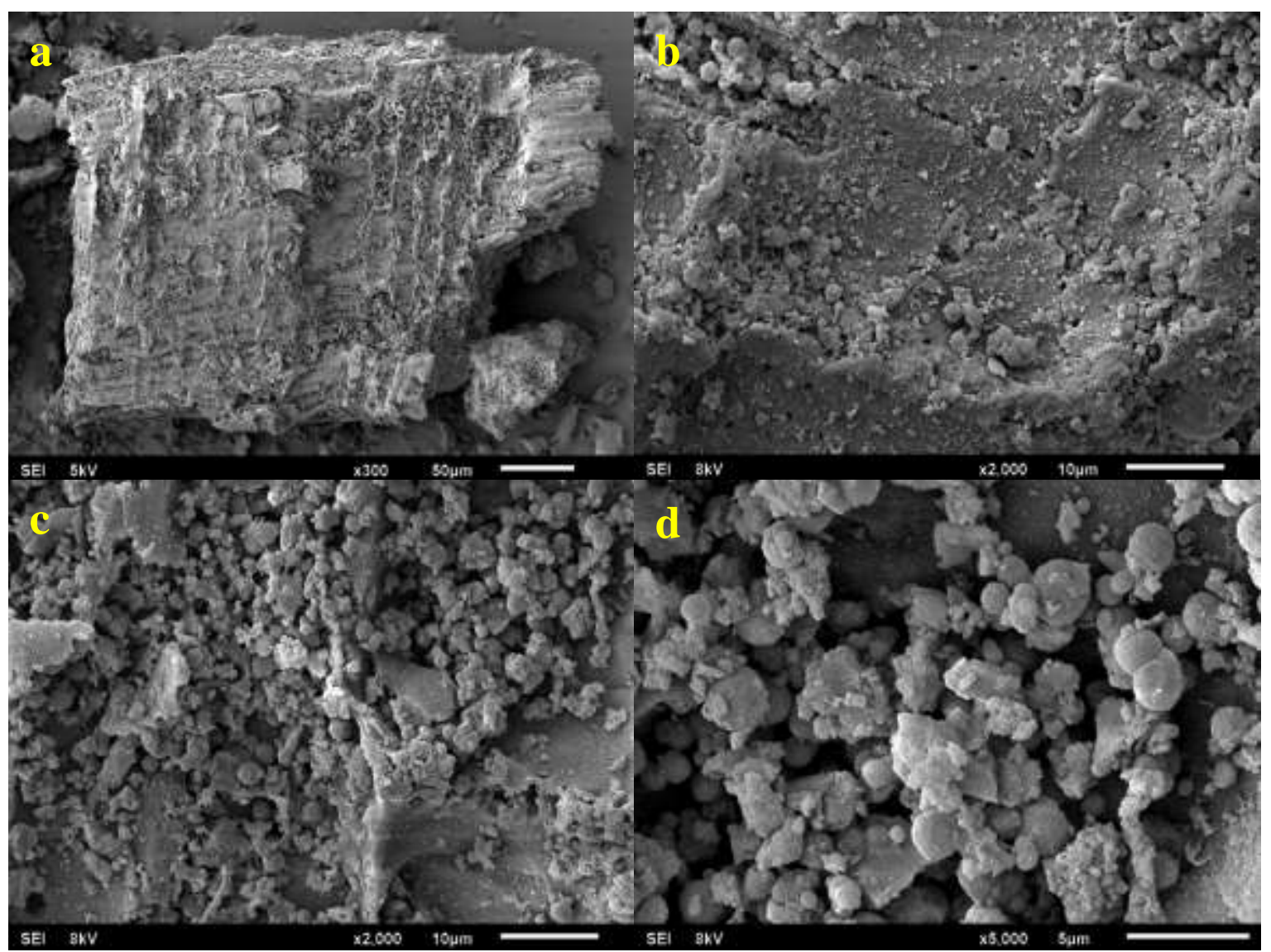

Fonte: Autores (2021).

Em destaque na Figura 3d aparecem os lúmens, vácuos, que são interiores ocos da célula. Os resultados morfológicos obtidos para o compósito de celulose-melamina-sílica são apresentados na Figura 4, que mostra a distribuição heterogênea de aglomerados esféricos na superfície da fibra. Estes aglomerados de partículas entre 1 e $2 \mu \mathrm{m}$ são devido à presença de nitrogênio $(\mathrm{N})$, oxigênio $(\mathrm{O})$, silício $(\mathrm{Si})$ e sódio $(\mathrm{Na})$.

\subsubsection{Espectroscopia por energia dispersiva (EDS)}

A análise de EDS da Figura 5 e da Figura 6 permitem a determinação da composição qualitativa e semiquantitativa dos elementos, por meio da emissão de espectros de raios X característicos, possibilitando a obtenção de perfis químicos que auxiliam no estudo da zona de interesse. Com isso, tem-se uma melhor elucidação da distribuição dos elementos na superfície do compósito (Krishnamachari et al., 2011; Pathania et al., 2020). 
Figura 5 - EDS para a celulose de Mangifera indica.
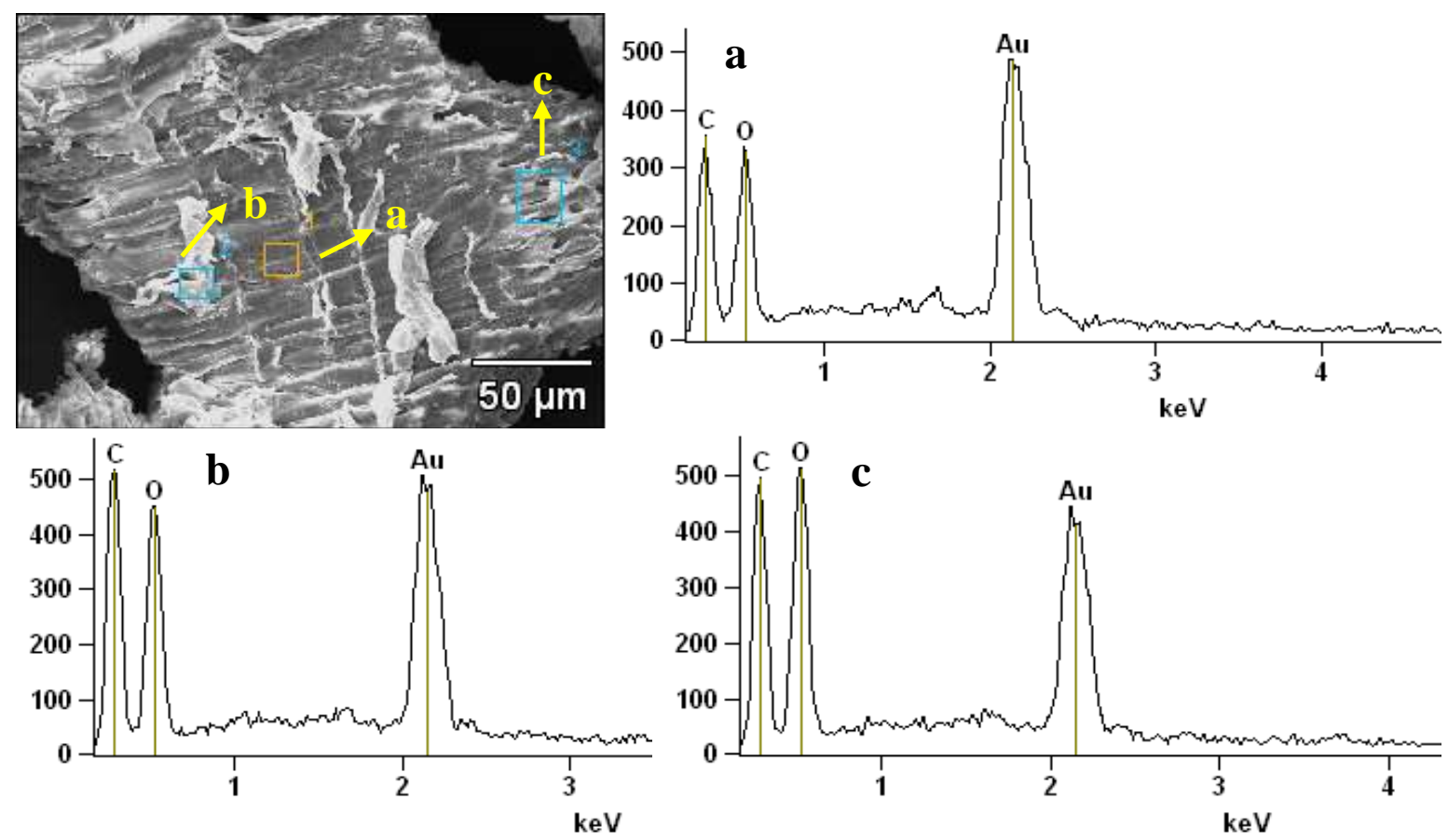

Fonte: Autores (2021).

Na Figura 5, observa-se a presença de carbono e oxigênio oriundos das fibras de celulose utilizada para a síntese do compósito. O sinal referente ao ouro (Au) que aparece é devido ao recobrimento do material condutor por Au durante as análises. Na Figura 6a, observa-se o aparecimento de picos $\mathrm{N}$ cuja presença é advinda da melamina utilizada para modificação da superfície da fibra de celulose. Na Figura 6 b e 6c, surgem bandas para os íons Si e o Na, provenientes do catalisador aplicado na síntese do compósito.

Figura 6 - Espectroscopia por energia dispersiva (EDS) para o compósito.
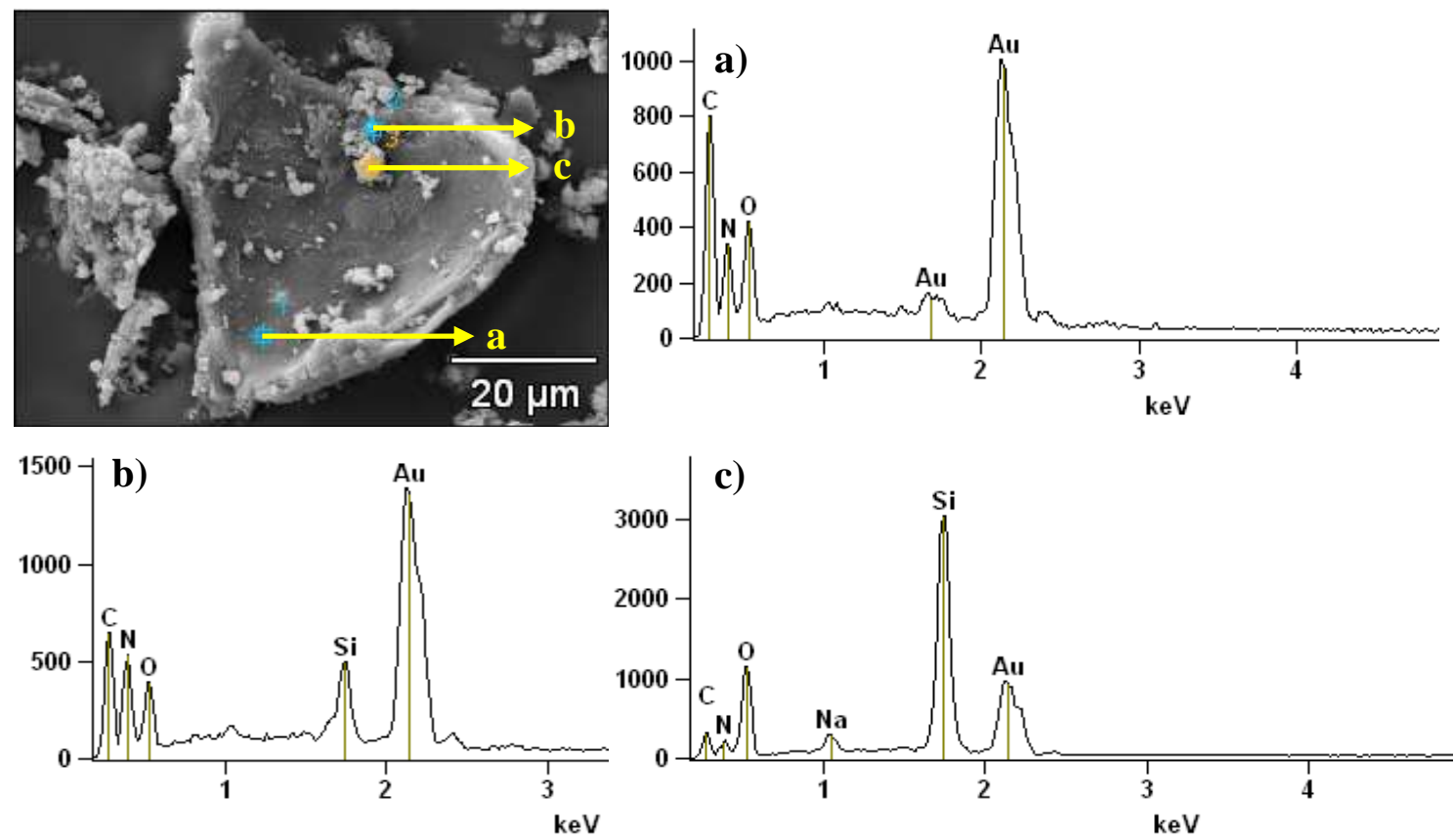

Fonte: Autores (2021). 


\subsubsection{Microscopia eletrônica de transmissão (MET)}

Na Figura 7a, 7c e 7e são apresentadas as imagens de MET para a celulose, nas quais observa-se a visualização da estrutura da celulose, do comprimento e do diâmetro. Nas Figuras 7b, 7d, 7f, 7g e 7h, aparecem as imagens em que se identifica a modificação do material com o aparecimento de estruturas esféricas e formação do compósito celulose-melaminasílica, formando uma mistura de materiais. Diferente do que ocorre no MEV, o MET oferece informações bidimensionais da amostra, por meio da ampliação da imagem formada pelo impacto dos elétrons transmitidos e difratados (Kwiecińska et al., 2019).

Figura 7 - MET para a celulose e o compósito, a) celulose - $1 \mu \mathrm{m}$; b) compósito - $1 \mu \mathrm{m}$; c) celulose - $100 \mathrm{~nm}$; d) compósito $100 \mathrm{~nm}$, e) celulose - $200 \mathrm{~nm}, \mathrm{f}$ ) compósito - $200 \mathrm{~nm}, \mathrm{~g}$ ) compósito - $500 \mathrm{~nm}, \mathrm{~h}$ ) compósito $50 \mathrm{~nm}$.

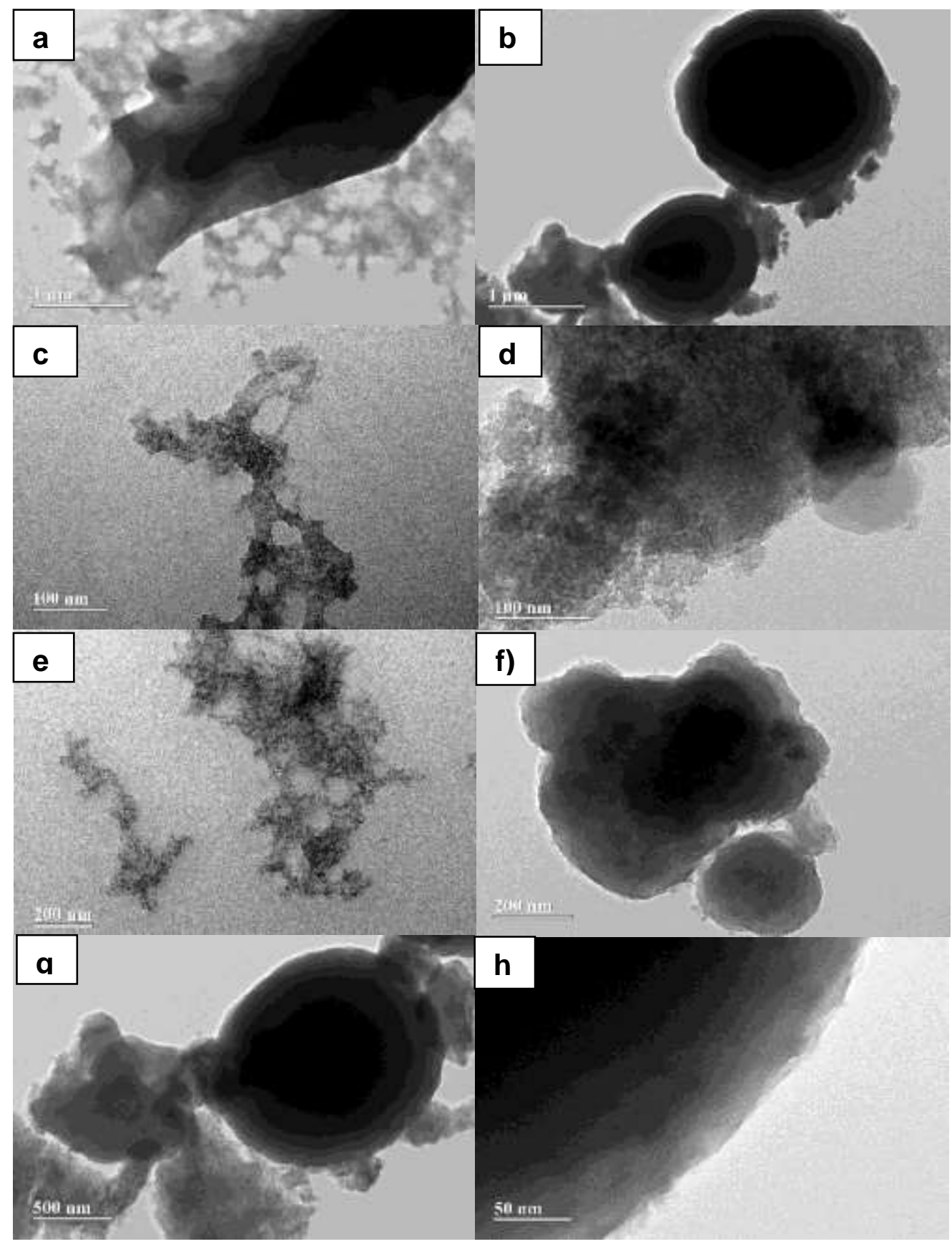

Fonte: Autores (2021). 


\subsubsection{Análise Termogravimétrica}

A técnica de termogravimetria consiste em submeter uma amostra a um programa de aquecimento controlado e avaliar a variação na massa da substância no decorrer do processo. Trata-se de uma técnica destrutiva, largamente utilizada na investigação da influência do aquecimento na massa de substâncias (Kamble et al., 2021a). As curvas de TG podem ser derivadas (primeira), com a obtenção da DTG (termogravimetria derivada) que informa a variação da massa em relação ao tempo ou a temperatura (Kamble et al., 2021b).

Figura 8 - Curvas de TG e DTG para a celulose de Mangifera indica.

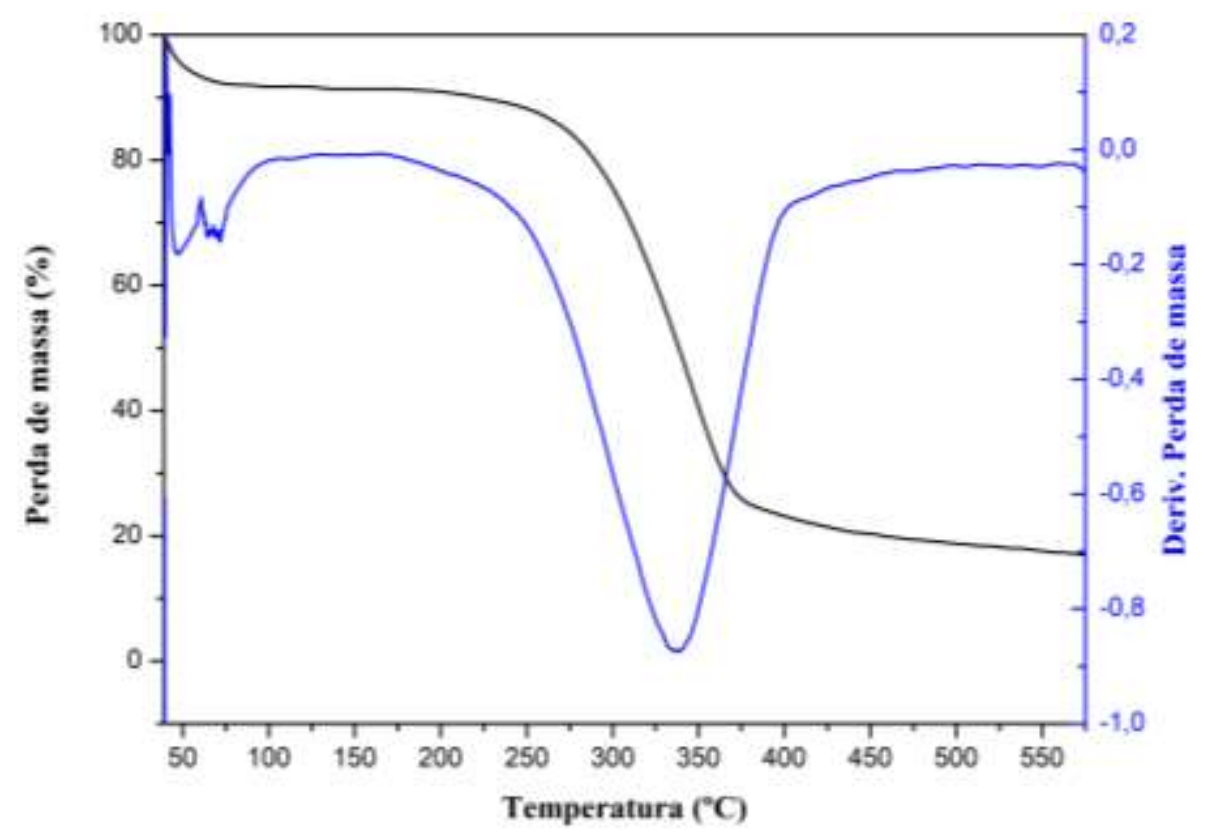

Fonte: Autores (2021).

O resultado para as curvas de TG/DTG para a celulose de Mangifera indica é apresentado na Figura 8. Pode-se observar que logo de início há uma pequena perda de massa em baixa temperatura, correspondente cerca de $9 \%$ da massa de amostra inicial, provavelmente devido à evaporação de água residual presente. O primeiro patamar de estabilização de massa ocorre por volta de $95{ }^{\circ} \mathrm{C}$. A temperatura de $180^{\circ} \mathrm{C}$ tem início uma perda acentuada de massa da celulose, aproximadamente $69 \%$, em $285^{\circ} \mathrm{C}$, e observa-se a temperatura onset, que corresponde ao início extrapolado do evento térmico.

A temperatura final indica o término da etapa de perda de massa e liberação da maior parte dos compostos voláteis, e a temperatura endset de $375{ }^{\circ} \mathrm{C}$ corresponde ao final do evento térmico extrapolado, e a estabilização ocorre por volta de 440 ${ }^{\circ} \mathrm{C}$. O segundo patamar de estabilização da massa se inicia por volta de $450{ }^{\circ} \mathrm{C}$, em que há a degradação da lignina, com liberação de compostos voláteis e a formação de carbono fixo, durante o processo de pirólise, a lignina remanescente na amostra derrete e cria uma fase líquida de elevada viscosidade, que atua como uma barreira retardante da liberação dos compostos voláteis, o que pode justificar a pequena perda de massa do material (3\%) nessa etapa final (Z. Zhang et al., 2018a). A curva de DTG confirma a ocorrência dos dois fenômenos, o primeiro é mais lento e relativo à perda de água e o segundo acontece entre 250 e $400{ }^{\circ} \mathrm{C}$ de ocorrência mais rápida e é no qual ocorre a efetiva degradação da celulose com perda máxima de massa para a maioria das amostras entre 300 a $450^{\circ} \mathrm{C}$ (Kamble et al., 2021c). 
Segundo Agwuncha et al. (2020d) a perda de massa acentuada deve-se a degradação da celulose e da hemicelulose, que corresponde a cerca de $65 \%$ do total das fibras vegetais. O processo para a celulose está diretamente relacionado ao arranjo das cadeias de celulose empacotadas na madeira. Assim, as diferenças organizacionais na cadeia de celulose, da Mangifera indica, podem afetar o comportamento da decomposição térmica para a amostra, ou seja, a estrutura da celulose também varia de acordo com a matéria prima da qual é extraída (Poletto et al., 2012; Zhang et al., 2018b). Após o fim do procedimento de termogravimetria, foi constatado que $85 \%$ da massa inicial da amostra foi degradada pela temperatura.

Figura 9 - Curvas de TG e DTG para o compósito celulose-melamina-sílica.

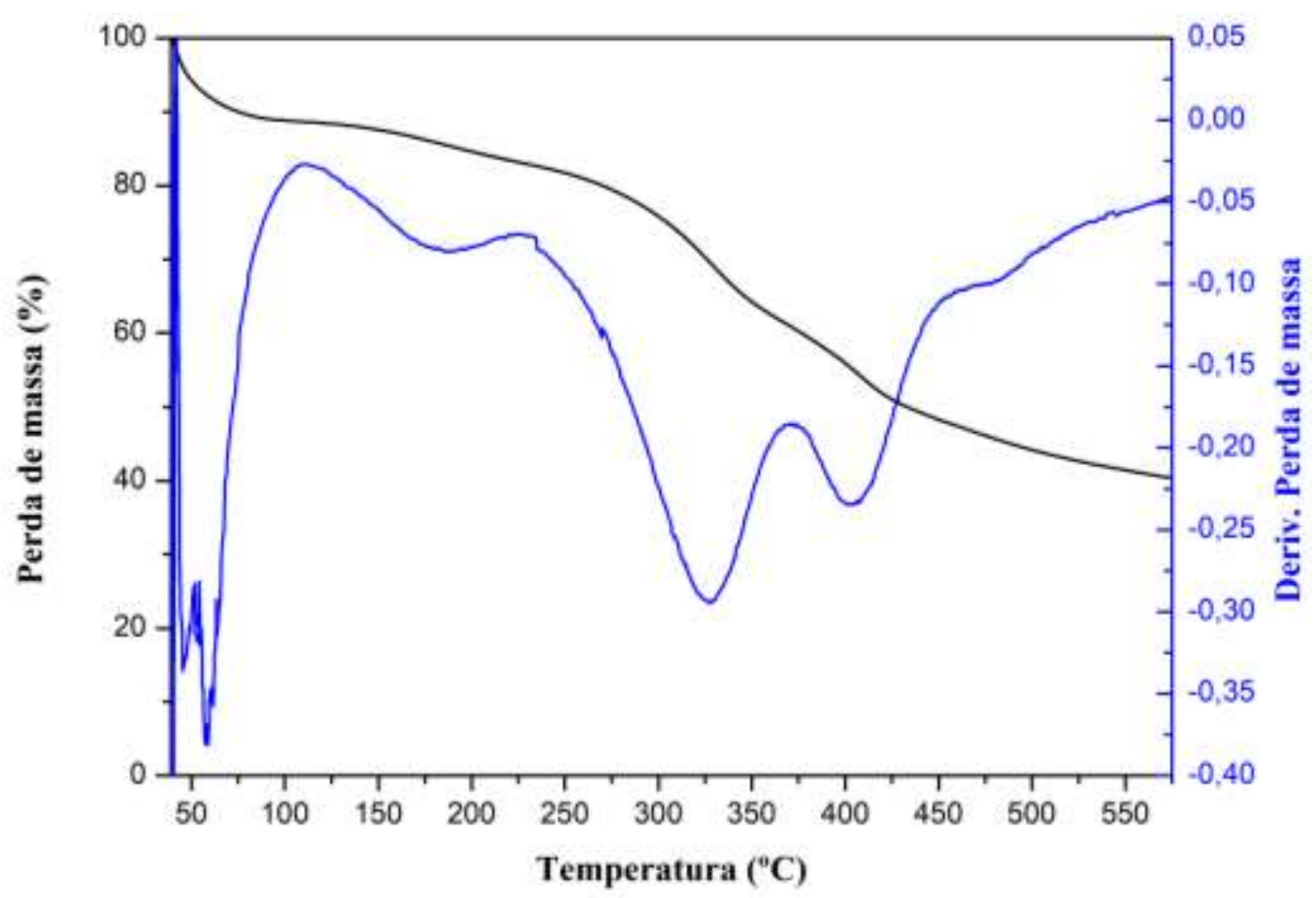

Fonte: Autores (2021).

Diferenças notáveis foram observadas entre as curvas de TG/DTG para o compósito em relação à celulose. Conforme a Figura 9, a perda de massa ocorre em número maior de etapas. Na fase inicial, assim como o observado para a celulose, constata-se a perda de água pela evaporação a baixas temperaturas, com variação na massa de $12 \%$. Em aproximadamente 110 ${ }^{\circ} \mathrm{C}$ a evaporação tem fim e há o início da segunda etapa de degradação do compósito que dura até $230{ }^{\circ} \mathrm{C}$ com perda de $6 \%$ durante esse intervalo de temperatura. A curva de TG apresenta uma suave anomalia entre 265 e $375{ }^{\circ} \mathrm{C}$ que é melhor observado na curva de DTG. Durante esse evento, houve perda de $20 \%$ de massa residual da amostra, e mais dois outros processos de degradação são observados, um entre 375 e $450{ }^{\circ} \mathrm{C}$ e o outro entre 460 e $510{ }^{\circ} \mathrm{C}$ com respectiva perda de massa de 6 e 7\%. Ao final do programa de aquecimento, houve degradação de aproximadamente $65 \%$ da massa inicial do compósito, o que sugere a maior estabilização térmica do material.

\subsubsection{Potencial zeta}

A determinação do potencial zeta é baseada na separação das cargas existentes na interface que se estabelece entre a superfície da partícula e o líquido em que elas estão dispersas. As medidas de potencial zeta são empregadas para estimar as cargas existentes na superfície das partículas (Choi et al., 2020). Essas cargas são responsáveis pelo efeito de repulsão, 
contribuindo para a maior estabilidade da suspensão em meio aquoso, dessarte, não há a ocorrência da formação de aglomerados entre as partículas (Crothers et al., 2021; Sharifi et al., 2021).

De acordo com a Figura 10, observa-se que, para valores de pH inferior a 3, o compósito apresenta potencial entre -20 e $5 \mathrm{mV}$, o que indica baixa estabilidade desse material em suspensão. Em suma, para a avaliação da estabilidade das suspensões, segue-se a regra de que os valores de potencial zeta maiores, o módulo de $30 \mathrm{mV}$, indicam partículas altamente carregadas, nas quais há o estabelecimento de dispersões físicas estáveis devido à repulsão eletrostática existente (Başaran Kankılıç \& Metin, 2020c).

Em pH próximo a 2,2 há a constatação do ponto isoelétrico do compósito, é nesse $\mathrm{pH}$ que ocorre o estabelecimento da condição de equivalência entre as cargas negativas e positivas. Para valores de $\mathrm{pH}$ superior a 3, o potencial zeta é mais negativo, e a partir do pH 5 o compósito adquire maior quantidade de cargas negativas, o que favorece as interações eletrostáticas e a maior estabilidade do sistema. A desprotonação da solução, as hidroxilas ( $\mathrm{OH}-$ ) presentes em grande número nas fibras de celulose do compósito e os grupos silicatos $\left(\mathrm{SiO}_{4}^{-2}\right)$, favorecem a predominância de cargas negativas superficiais em detrimento das cargas positivas, o que pode justificar a ocorrência de valores negativos para o potencial zeta a partir do $\mathrm{pH}$ 2,2. Portanto, a estabilidade das dispersões aquosas de fibras de celulose é diretamente influenciada pela dupla camada elétrica que se estabelece sob sua superfície (Başaran Kankılıç \& Metin, 2020d).

Figura 10 - Potencial Zeta para o compósito celulose-melamina-sílica em diferentes pH.

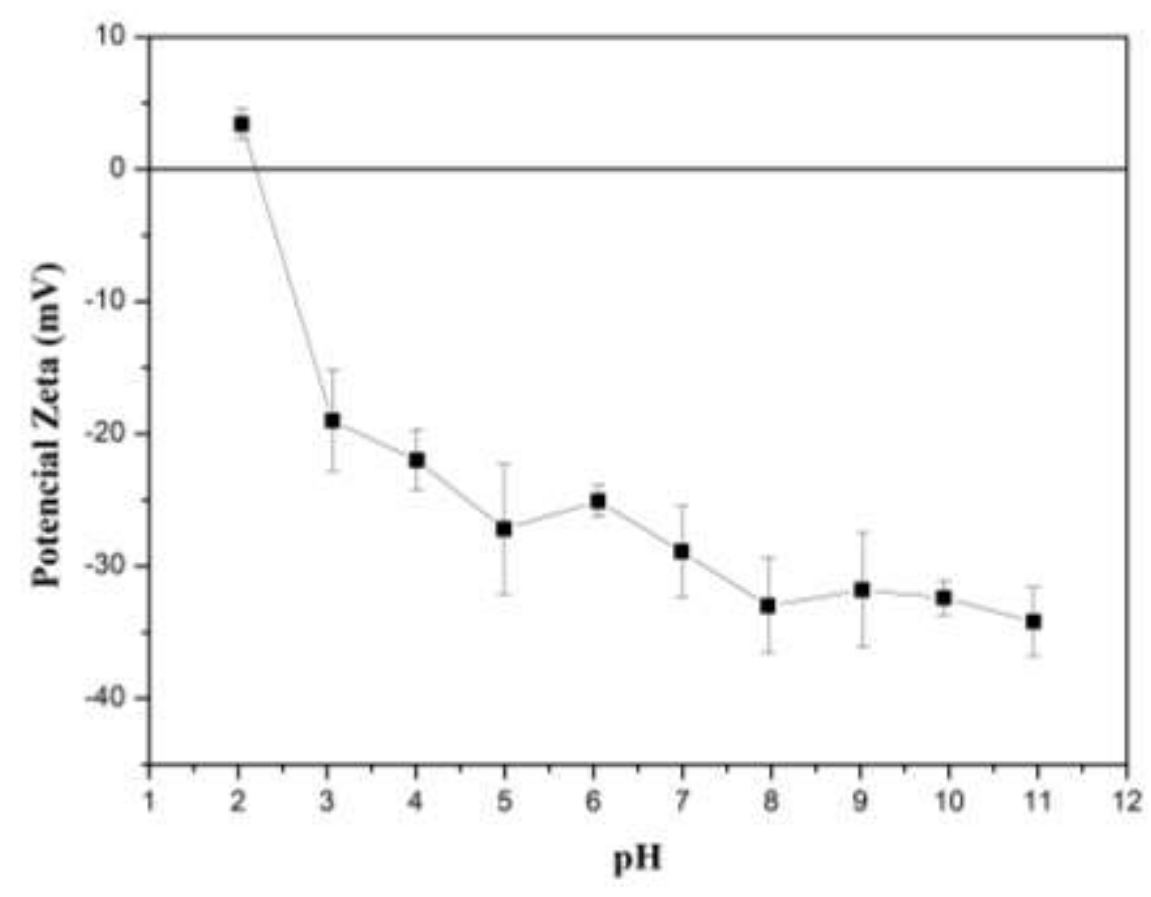

Fonte: Autores (2021).

Para pH na faixa de 3 a 7, observa-se que há o incremento progressivo dos valores negativos para o potencial zeta, de $-19 \pm 3,8$ a $-28,9 \pm 3,4 \mathrm{mV}$, respectivamente. A partir do pH 5 o valor para o potencial zeta apresenta maior estabilização, e portanto há o incremento do caráter aniônico do compósito celulose-melamina-sílica, que está de acordo com o observado no FT-IT com a presença dos grupos carbonilas e hidroxilas, fato que também foi observado por Haque et al. (2020b), no estudo da adsorção de azul de metileno em bioadsorventes de resíduos provenientes do descaroçamento de algodão. $\mathrm{O}$ aumento da presença de cargas negativas na superfície do compósito favorece a interação eletrostática com as moléculas de corantes catiônicos, como por exemplo, o azul de metileno, resultando no incremento da eficiência de remoção do corante na faixa de 
pH que apresentava valores mais negativos para o potencial zeta (Başaran Kank1liç \& Metin, 2020e; El-Bouraie, 2015; Wang et al., 2019).

\subsection{Otimização das variáveis tempo e massa de compósito}

Para a obtenção da melhor condição de aplicação do compósito na retenção do corante de azul de metileno foi feito o estudo das variáveis massa (x1) e tempo (x2) por meio do planejamento composto central (Tabela 2). A quantificação do teor do corante foi realizada por meio da curva de calibração apresentada na Figura 11, na qual a faixa de trabalho foi de 1 a 5 ppm. A equação que descreve a concentração da solução foi $\mathrm{y}=0,191 \mathrm{x}-0,0119$, na qual y corresponde a absorbância e $\mathrm{x}$ é a concentração expressa em ppm, e o coeficiente de determinação entre a absorbância e concentração das soluções foi de 0,9994.

Figura 11 - Curva de calibração para o azul de metileno.

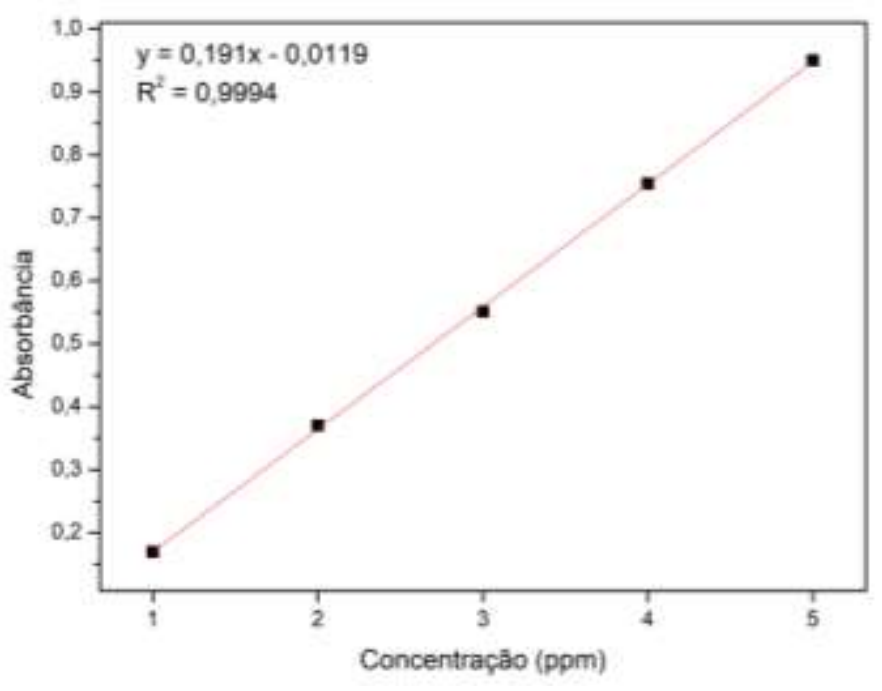

Fonte: Autores (2021).

De acordo com o resultado apresentado na Tabela 2 para o percentual de retenção do corante pelo compósito, observase que os ensaios E1, E2 e E5 foram os que apresentaram o menor percentual de retenção, e o ensaio E4 juntamente com os pontos centrais (E9, E10 e E11) apresentaram os resultados mais elevados.

Tabela 2 - Porcentagem de retenção do azul de metileno pelo compósito

\begin{tabular}{cccc}
\hline \multirow{2}{*}{ Ensaios } & \multicolumn{2}{c}{ Variáveis independentes } & Retenção \% \\
Massa $\left(x_{1}\right)$ & $40(-1)$ & $20(-1)$ & 69,3 \\
E2 & $40(-1)$ & $40(+1)$ & 73,1 \\
E3 & $80(+1)$ & $20(-1)$ & 87,4 \\
E4 & $80(+1)$ & $40(+1)$ & 89,3 \\
E5 & $32(-\sqrt{2})$ & $30(0)$ & 68,1 \\
E6 & $88(+\sqrt{2})$ & $30(0)$ & 88,1 \\
E7 & $60(0)$ & $14(-\sqrt{2})$ & 79,2 \\
E8 & $60(0)$ & $44(+\sqrt{2})$ & 82,5 \\
E10 & $60(0)$ & $30(0)$ & 88,6 \\
E11 & $60(0)$ & $30(0)$ & 88,8 \\
\hline
\end{tabular}

Fonte: Autores (2021). 
Os resultados experimentais obtidos com a realização do planejamento experimental foram ajustados a uma equação polinomial de segunda ordem para expressar a relação entre as variáveis massa $(m)$ e tempo (t) em relação à resposta porcentagem de retenção do corante:

$$
R \%=88,6+15,6 m-10,3 m^{2}+2,5 t-7,6 t^{2}
$$

O fator que apresenta maior significância dentre os termos é o termo linear para a massa $(p=0,0000)$, seguido pelo termo quadrático para a massa $(\mathrm{p}=0,0000)$ e o termo linear para o tempo $(\mathrm{p}=0,0157)$. A interação entre a massa e o tempo $(\mathrm{p}$ $=0,3919)$ não foi significativa $(\mathrm{p}>0,05)$ para o modelo. As Figuras de mérito para o modelo estão dispostas na ANOVA da Tabela 3.

Tabela 3 - ANOVA para o modelo quadrático para o planejamento composto central.

\begin{tabular}{lcccc}
\hline \multicolumn{1}{c}{ Fator } & $\begin{array}{c}\text { Soma } \\
\text { Quadrática }\end{array}$ & $\begin{array}{c}\text { Graus de } \\
\text { Liberdade }\end{array}$ & $\begin{array}{c}\text { Média } \\
\text { Quadrática }\end{array}$ & Valor de $\boldsymbol{p}$ \\
\hline Massa (L) & 489,39 & 1 & 489,39 & 0,0000 \\
Massa (Q) & 150,61 & 1 & 150,61 & 0,0000 \\
Tempo (L) & 12,96 & 1 & 12,96 & 0,0157 \\
Tempo (Q) & 81,12 & 1 & 81,12 & 0,0003 \\
1L por 2L & 0,88 & 1 & 0,88 & 0,3919 \\
Erro & 5,02 & 5 & 0,04 & \\
Ajuste total & 690,75 & 10 & & \\
$\mathbf{R}^{\mathbf{2}}$ & 0,9927 & & & \\
$\mathbf{R}$ ajustado & 0,9855 & & & \\
\hline
\end{tabular}

Fonte: Autores (2021).

A constatação da maior significância da massa em detrimento do tempo pode ser confirmada pela significância dos fatores apresentados na ANOVA. De acordo com a Tabela 3, o coeficiente de determinação múltipla $\mathrm{R}^{2}$, descreve cerca de 99,80\% da variância dos dados, com uma máxima variância explicada de 98,55\%.

A Figura 12a mostra que existe uma correlação entre os valores experimentais e os valores previstos pelo modelo, revelando que é capaz de prever com boa exatidão os valores experimentais. A análise dos resíduos do modelo, Figura 12b, demonstrou que os mesmos seguem uma distribuição normal, indicando que as variações nas medidas realizadas resultam de erros aleatórios e inerentes ao processo analítico.

Figura 12 - (a) Gráfico dos valores experimentais vs valores previstos e (b) histograma de resíduos vs frequência.
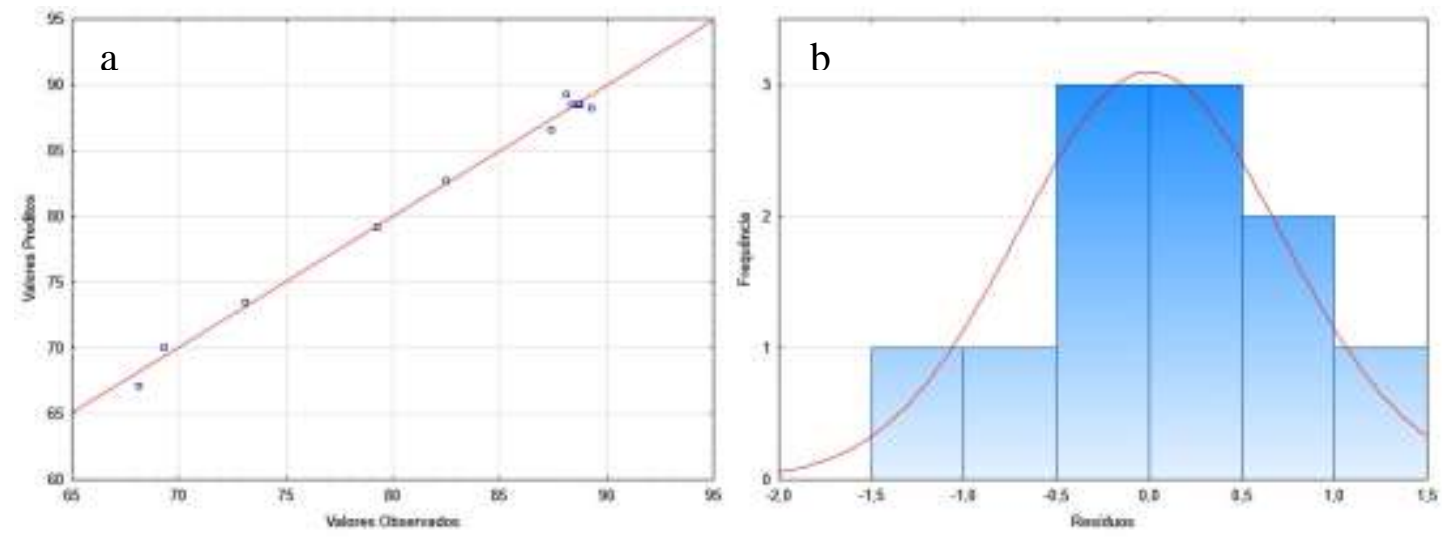

Fonte: Autores (2021). 
Após a avaliação da significância dos efeitos e da adequação do modelo quadrático pela ANOVA, foi obtida a superfície de resposta, Figura 13, para o efeito da massa e do tempo no teor de corante retido pelo compósito. A superfície de resposta indica que o maior percentual de retenção do corante pode ser obtido utilizando níveis de massa e tempo localizados próximos ao ponto central para massa (0) e tempo (0), $60 \mathrm{mg}$ e 30 minutos, respectivamente.

Figura 13 - Superfície de resposta do modelo quadrático para o planejamento composto central.

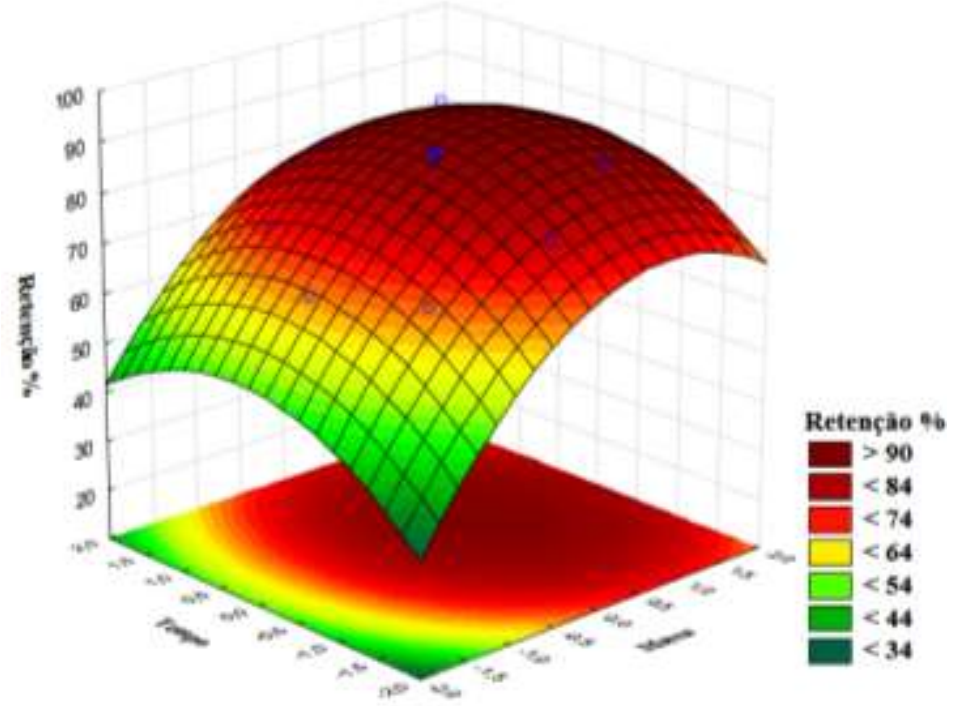

Fonte: Autores (2021).

Em termos de massa, observou-se que há o aumento da eficiência na medida em que se anda na superfície de resposta (Figura 13) do nível baixo $(-1,40 \mathrm{mg})$ para o ponto central $(0,60 \mathrm{mg})$. Deste modo, pode-se inferir que quantidades de massa inferiores a $60 \mathrm{mg}$ não foram eficazes em reter maiores quantidades de corante, ademais, após o ponto central há um leve decréscimo da eficiência. Para a variável tempo, nos níveis mais baixos (-1, 20 minutos), encontrou-se a menor eficiência de extração, sendo possível constatar que em tempos inferiores a 30 minutos não propiciaram uma condição favorável para que o compósito possa interagir com o corante e capturá-lo do meio, fato que foi alcançado por volta de 30 minutos (ponto central, $0)$.

A avaliação da viabilidade do poli (cloreto de trimesoíla-melamina) para a remoção de metileno e metais tóxicos, foi estudada por AL-Hammadi et al. (2018c) por meio de uma análise univariada. Esses autores observaram que, para soluções de azul de metileno nas concentrações de 3 e 16 ppm entre 0 e 30 minutos, houve o incremento pronunciado da taxa de remoção do corante pelo material, no qual, em 30 minutos ocorre o percentual máximo de remoção e após esse tempo há a ocorrência do equilíbrio. Por outro lado, ao avaliar a adsorção de azul de metileno por sílica mesoporosa preparada pelo método sol-gel com hidroxietil celulose, Lyu et al. (2020c) verificaram que era necessário tempos de contato entre o compósito e o corante superiores a 80 minutos para propiciar uma adsorção efetiva, com a estabilização da adsorção em 230 minutos, resultado parecido com o Yu et al. (2021) em que a redução efetiva da concentração do corante pelo compósito iniciou-se por volta de 120 minutos, com a remoção máxima sendo alcança em 150 minutos.

Ao comparar o tempo necessário para a efetiva remoção do corante azul de metileno pelo compósito, constatou-se que o compósito desenvolvido neste trabalho apresentou tempo similar ou menor para alcançar a remoção satisfatória do corante. Bonetto et al. (2021a) aplicaram um planejamento fatorial completo $3^{3}$ para estudar a significância da concentração inicial de azul de metileno, massa de adsorvente, $\mathrm{pH}$, temperatura e velocidade de agitação, e observaram que temperatura e velocidade 
de agitação não exerceram influência significativa na resposta, em que pH 10 e 85 mg são mais eficientes e, com o aumento da concentração do corante, há o decréscimo da eficiência de remoção. Moghazy et al. (2019), através de um planejamento fatorial completo $2^{4}$, observaram que tempo e massa de biossorvente foram os fatores mais significativos e que temperatura não exerceu atividade significativa.

$\mathrm{Na}$ análise dos resultados para a remoção do corante da tabela 2 foi possível constatar os três ensaios E1, E2 e E5, os quais foram feitos os que apresentaram o menor percentual de remoção, embora tenham sido realizados nos tempos de $20,40 \mathrm{e}$ 30 minutos, foram concluídos com as menores massas propostas pelo planejamento, e assim, podemos sugerir que valores de massa inferiores a $40 \mathrm{mg}$ não possibilitaram uma retenção mais pronunciada do corante.

Os experimentos E4, E6, E9, E10 e E11 apresentaram valores de retenção do corante superior a 88\%. O E4 foi realizado com a maior massa proposta de $80 \mathrm{mg}$, e no segundo maior tempo de 40 minutos. Quando comparado aos ensaios realizados no ponto central E9, E10 e E11, que foram realizados com $60 \mathrm{mg}$ e 30 minutos, verificou-se a proximidade de resultados. Como não há diferença significativa entre os percentuais, logo, os ensaios realizados com $60 \mathrm{mg}$ e 30 minutos, foram mais vantajosos que o $\mathrm{E} 4$, pois utilizaram menor massa e realizados em menor tempo.

O gráfico de contorno apresentado na Figura 14 mostra a disposição dos experimentos no espaço amostral, a área em vermelho mais escuro, corresponde à região proposta pelo planejamento em que se teve a maior eficiência de retenção. A análise numérica indicou que a melhor condição, segundo o modelo matemático, para a aplicação do compósito corresponde à massa de $74 \mathrm{mg}$ e ao tempo de 37 minutos, e a retenção nessa condição seria 89,3\% (desejabilidade de 0,9998). Ainda que a melhor condição proposta pela modelagem matemática propicie $89,3 \%$ de retenção do corante, essa pode não ser a condição mais viável de aplicação, pois no ponto central (60 mg, 30 minutos) foi retido um percentual considerável. Para alcançar a porcentagem predita pelo modelo $(89,3 \%)$ foi necessário o incremento de $23,3 \%$ na quantidade de massa do compósito e do tempo de contato o que ocasionaria a elevação dos custos operacionais do processo durante o tratamento primário quimicamente assistido.

Figura 14 - Gráfico de contorno do modelo quadrático para o planejamento composto central.

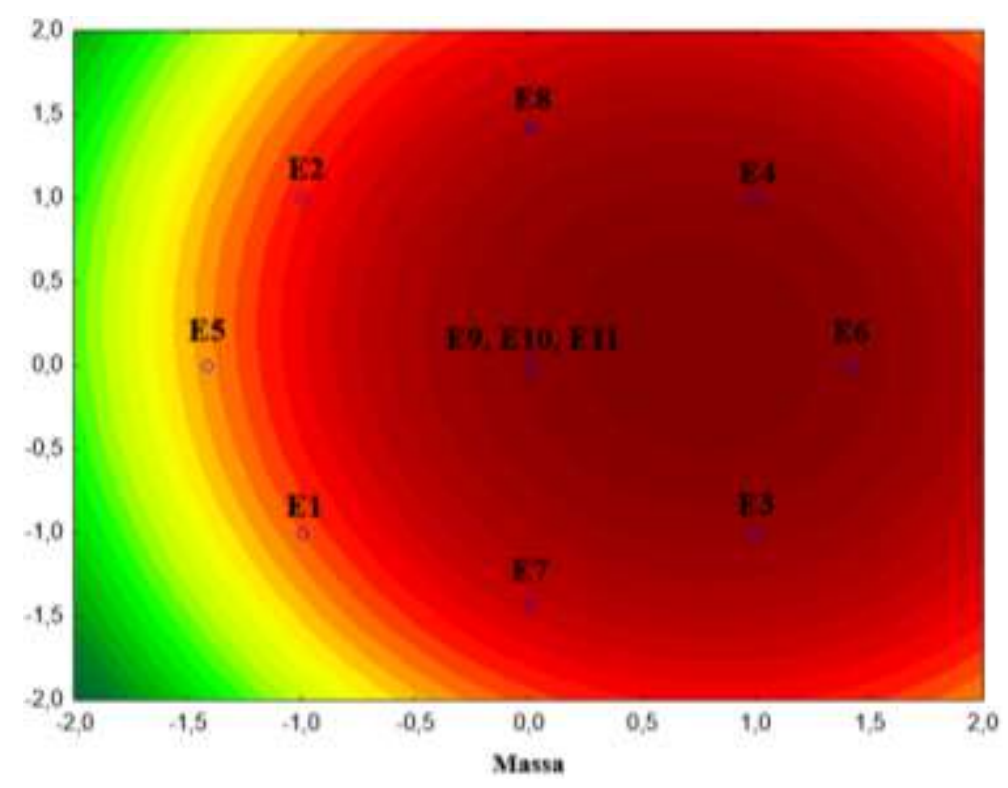

Fonte: Autores (2021). 


\subsection{Aplicação da condição ótima na adsorção de azul de metileno}

Após a avaliação dos fatores, massa de compósito e tempo de contato, a condição escolhida para a aplicação do compósito, representada pelo ponto central (60 mg e 30 minutos), foi testada quanto a adsorção do corante azul de metileno nas concentrações de 1, 2, 3, 4 e 5 ppm. A Tabela 4 e a Figura 15 apresentam a concentração do corante, antes e depois da aplicação. Entre as cinco concentrações avaliadas, a solução mais concentrada, a de 5 ppm foi a que apresentou a menor taxa de retenção do corante, com $75 \%$.

Figura 15 - Espectro visível para as soluções de azul de metileno antes (a) e depois da aplicação do compósito (b). c) percentual de corante removido.
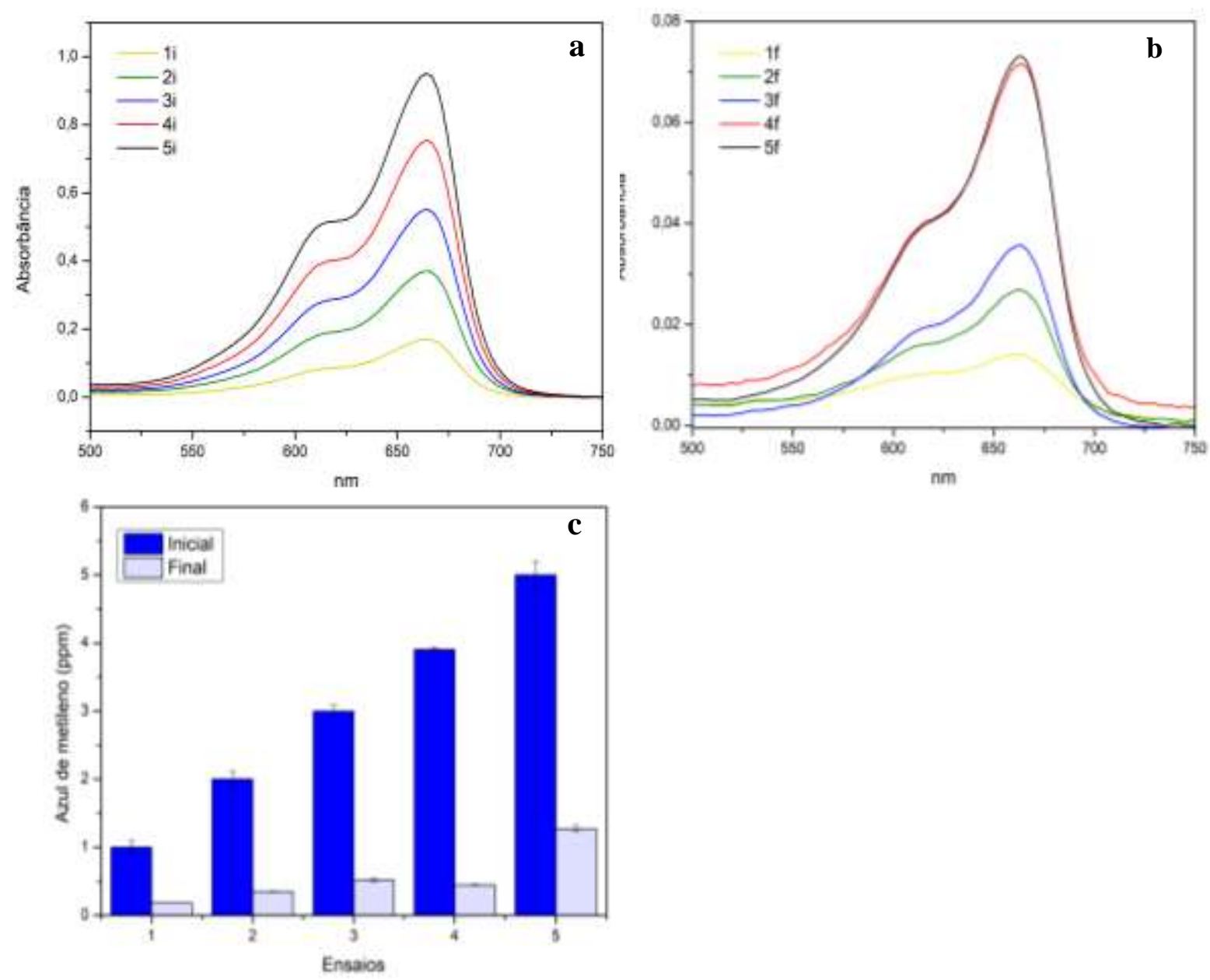

Fonte: Autores (2021).

A diminuição do percentual de retenção com o incremento da concentração também foi observada por AL-Hammadi et al. (2018d) cuja capacidade de adsorção do compósito policloreto de trimetil-melamina (PTMP) diminuiu a partir de 3 ppm de concentração azul de metileno. Esse fato pode ser justificado pela saturação dos sítios disponíveis para a captura do corante. 
Tabela 4 - Concentração de azul de metileno (ppm) antes e após a aplicação do compósito

\begin{tabular}{ccc}
\hline Concentração Inicial & Concentração Final & Remoção (\%) \\
\hline 1 & $0,18 \pm 0,00$ & $81,7 \pm 0,2$ \\
2 & $0,35 \pm 0,00$ & $82,5 \pm 0,4$ \\
3 & $0,52 \pm 0,02$ & $82,7 \pm 0,7$ \\
4 & $0,74 \pm 0,00$ & $88,6 \pm 0,2$ \\
5 & $1,27 \pm 0,04$ & $74,6 \pm 0,9$ \\
\hline
\end{tabular}

Fonte: Autores (2021).

Para concentrações inferiores 5 ppm, o compósito apresentou percentual de remoção superior a 80\%, em que a maior eficiência foi observada para a solução de 4 ppm alcançando a retenção máxima de 88,6 \%. Com isso, esta pesquisa desenvolveu um compósito simples, ecológico e de baixo custo, pois reaproveitou resíduos de podas de Mangifera indica, que foi eficaz na retenção de azul de metileno, e com potencialidade para ser aplicado para o tratamento primário quimicamente assistido de efluentes da indústria têxtil.

\subsection{Efeito do pH na adsorção de azul de metileno}

$\mathrm{O}$ pH da solução afeta diretamente o processo de adsorção, contribuindo para o aumento ou diminuição da eficiência do procedimento. Cada corante se comporta de uma maneira particular perante as variações no pH do meio em questão, visto que, trata-se de um soluto que possui carga superficial característica (Banerjee et al., 2015). Na Figura 16 são apresentados os percentuais de retenção do corante pelo compósito celulose-melamina-sílica. Observou-se que há o aumento pronunciado na retenção do corante na faixa de $\mathrm{pH}$ de 2 a 4 . No pH 2, mais ácido, foi observado a menor eficiência do processo, com remoção de 14,8 $\pm 0,6 \%$. A menor eficiência em pH mais ácido pode ser explicado pela presença de íons $\mathrm{H}+\mathrm{em}$ excesso, que durante a adsorção, competem com o corante - azul de metileno - que também é carregado positivamente pelos sítios do compósito (Tang et al., 2017). Com o aumento do caráter alcalino da solução, o percentual de remoção aumenta, no qual em pH 5 há a remoção de 79,0 $\pm 0,2 \%$, e a partir disso, a eficiência se mantém acima de $80 \%$, além disso, o maior percentual de remoção foi observado em $\mathrm{pH} 11$, com 95,6 $\pm 0,2 \%$. Sendo assim, o compósito possui ampla aplicabilidade quanto a faixa de $\mathrm{pH}$, podendo atuar de maneira eficiente em $\mathrm{pH}$ superiores a 5 . 
Figura 16 - Percentual de remoção de acordo com a variação de Ph.

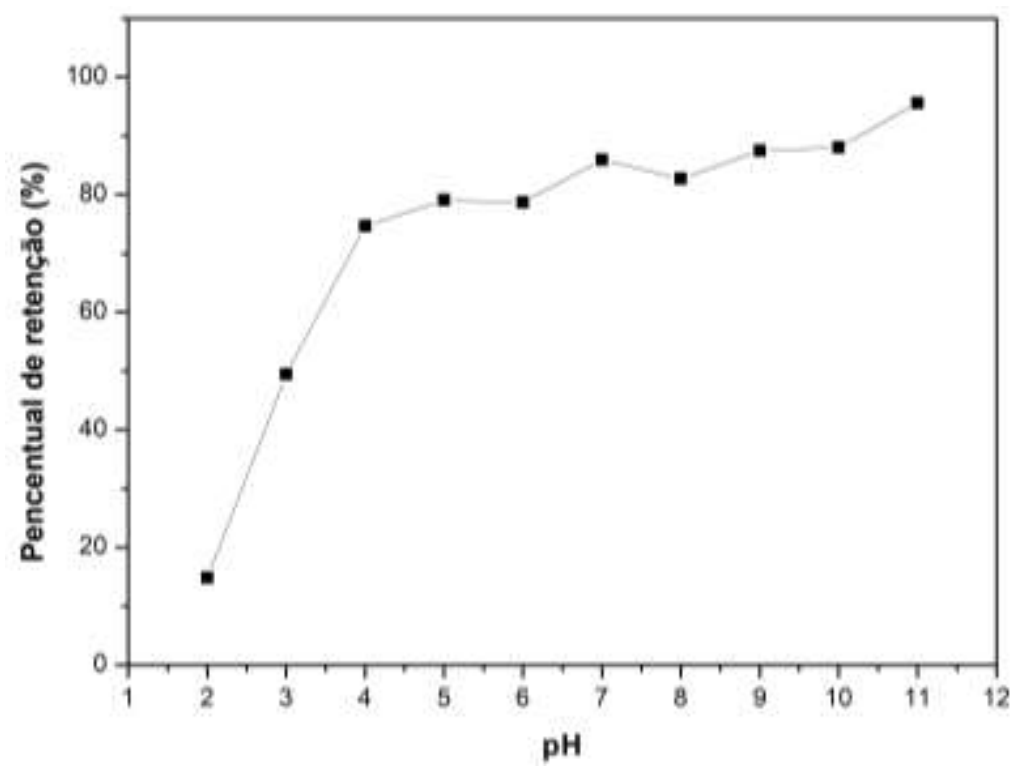

Fonte: Autores (2021).

A avaliação do pH está em consonância com os resultados do potencial zeta, na qual, a partir do pH 5, há a estabilização e ocorre o aumento do caráter aniônico do compósito e isso implica no aumento da atração eletrostática entre o compósito aniônico e o corante catiônico. A presença de carga superficial negativa no compósito atrai os cátions do corante dispersos em solução, com o aumento do pH há aumento da capacidade de adsorção para corantes catiônicos (Banerjee et al., 2015; Bonetto et al., 2021b).

No estudo da biossorção do azul de metileno por compósitos de duas espécies de macroalgas Ulva fasciata e Sargassum dentifolium, Moghazy et al. (2019) observaram que após 6,7 e 9, respectivamente, as partículas de compósito começam a ser carregadas negativamente, e que em soluções de $\mathrm{pH}$ mais alto, a biossorção de moléculas carregadas positivamente, como os corantes catiônicos, é eletrostaticamente favorável. AL-Hammadi et al. (2018e) reportaram que a remoção do azul de metileno pelo compósito Poli (cloreto de trimesoíla-melamina) começa a ser efetiva a partir do pH 3. Esse fato também foi constatado por Wang et al. (2019) que convalidam a eficiência na adsorção do corante pelo compósito a base de polianilina e $\mathrm{TiO}_{2}$.

\subsection{Isoterma de adsorção}

Por meio das isotermas de adsorção é possível obter informações sobre os parâmetros físico-químicos que influenciam na aplicabilidade de um determinado material. As equações isotérmicas descrevem o equilíbrio que se estabelece durante esse processo e propiciam informações sobre a afinidade do adsorbato (azul de metileno) e o adsorvente (compósito) em condições controladas de $\mathrm{pH}$ e temperatura (Ho et al., 2002). A teoria relacionada à isoterma de Langmuir é a da formação de uma monocamada de adsorbato a superfície de um adsorvente, e, desse modo, há o estabelecimento de um equilíbrio que se constata a saturação do adsorvente (Haque et al., 2020c).

Os dados da adsorção do corante azul de metileno, pelo compósito celulose-melamina-sílica foram analisados de acordo com a forma linear da isoterma de Langmuir. A concentração do corante verificada no equilíbrio $\left(\mathrm{C}_{\mathrm{e}}\right)$ foi obtida após o teste de adsorção na faixa de contração de 5 a $500 \mathrm{mg} \mathrm{L}^{-1}$, e a capacidade de adsorção ( $\mathrm{q}_{\mathrm{e}}$ ) foi determinada pela Equação 2. A isoterma de adsorção obtida é apresentada na Figura 17a. A isoterma teórica é uma função hiperbólica e pode ser obtida pela 
Equação 3. A linearização é uma forma mais simples para a obtenção dos parâmetros, e a forma linear (Equação 4) foi empregada na determinação da capacidade máxima de adsorção $\left(\mathrm{q}_{\max }\right)$ e da constante de Langmuir $\left(\mathrm{K}_{\mathrm{L}}\right)$.

$$
\begin{array}{ll}
q_{e}=\frac{q_{\max } K_{L} C_{g}}{1+K_{L} C_{g}} & \text { Equação 3 } \\
\frac{C_{g}}{Q_{g}}=\frac{1}{q_{\pi v a x}} C_{e}+\frac{1}{q_{\max } K_{L}} & \text { Equação 4 }
\end{array}
$$

Figura 17 - (a) Isoterma de adsorção do azul de metileno pelo compósito celulose-melamina-sílica. (b) isoterma de adsorção na forma linear.
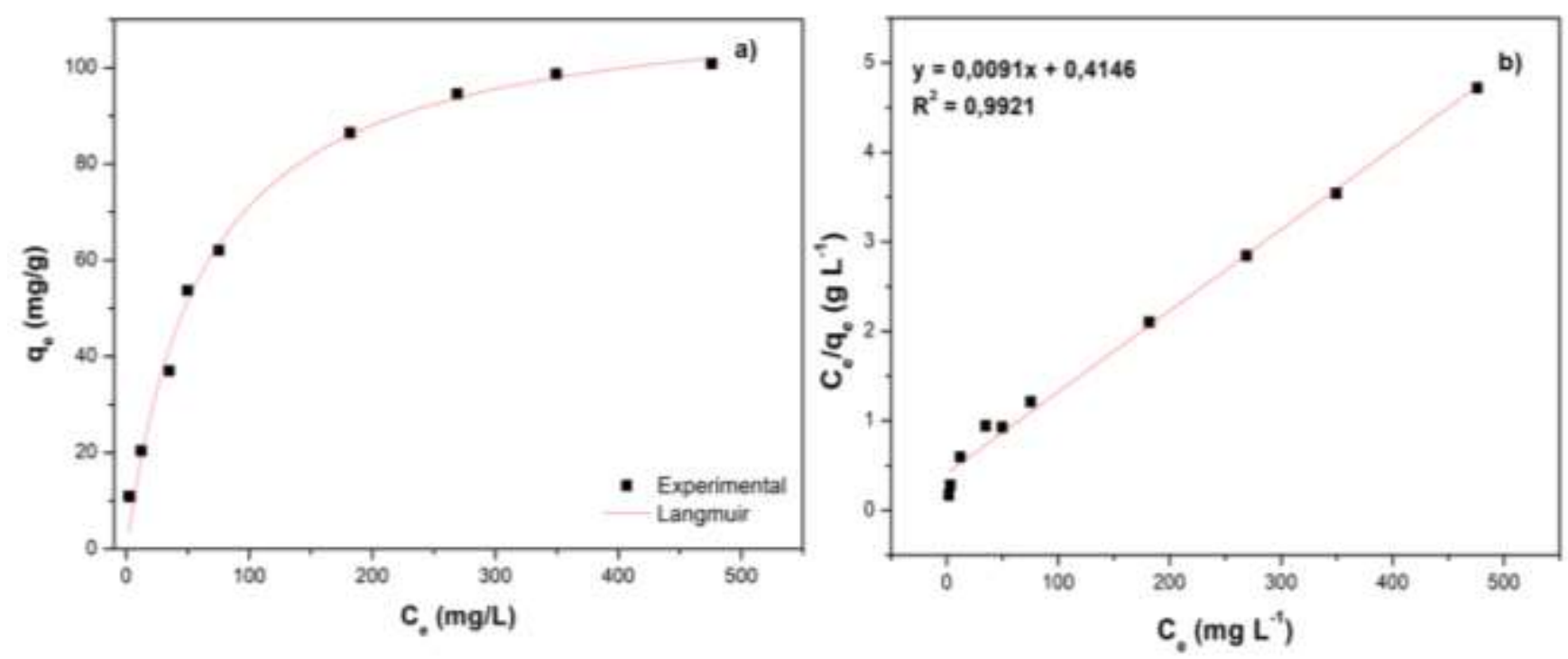

Fonte: Autores (2021).

O coeficiente angular da reta apresentada na Figura 17b permite encontrar o valor para o $\mathrm{q}_{\max }$, igual a $109,9 \mathrm{mg}^{-1} \mathrm{e}$ $\mathrm{K}_{\mathrm{L}}$ equivalente a $2,19 \times 10^{-2} \mathrm{~L} \mathrm{mg}^{-1}$. O coeficiente de regressão de 0,9921 mostra que o experimento de adsorção do azul de metileno pelo compósito teve bom ajuste ao modelo de Langmuir. O valor de $\mathrm{q}_{\max }$ costuma ser utilizado na comparação de vários adsorventes a mesma temperatura. $\mathrm{O}$ valor para o $\mathrm{q}_{\max }$ encontrado neste trabalho foi superior a outros reportados na literatura, conforme o valor apresentado de alguns resíduos agroindustriais como, por exemplo, a casca do ovo (Tsai et al., 2006), os resíduos de maracujá (Pavan et al., 2008) e o bagaço da azeitona (Banat et al., 2007). O valor de qmax foi próximo ao observado para os resíduos sólidos da indústria de suco de maçã apresentado por Bonetto et al. (2021c) de 107,6 mg g-1.

$\mathrm{O}$ valor da constante de Langmuir $\left(\mathrm{K}_{\mathrm{L}}\right)$ está diretamente relacionado à afinidade existente entre o adsorvente e o adsorbato, correspondendo à concentração de equilíbrio do corante azul de metileno quando o qe é metade do valor de qm (Bonetto et al., 2021d). Maiores valores de $\mathrm{K}_{\mathrm{L}}$ sugerem maior interação entre o par adsorvente-adsorbado, uma vez que a capacidade máxima de adsorção é alcançada quando os valores de $\mathrm{C}_{\mathrm{e}}$ são menores, isso implica que há mais moléculas de corante adsorvidas na superfície do compósito do que dispersas na solução (Haque et al., 2020d). 


\section{Conclusão}

Este trabalho apresenta resultados inéditos para a adsorção de azul de metileno por um compósito obtido a partir da celulose de resíduos de poda da Mangifera indica. O espectro de FT-IR mostrou que, após a síntese, persistiu a banda característica da melamina em $815 \mathrm{~cm}^{-1}$ no compósito. O MEV e o MET permitiram constatar que a celulose da Mangifera indica é bastante rugosa e que os $\mathrm{N}$ oriundos da melanina ficaram dispersos na superfície do compósito. O TG/DTG mostrou que o compósito é termicamente mais estável que a celulose mercerizada. A análise do potencial zeta mostrou que o compósito apresenta maior estabilização a partir do $\mathrm{pH} \mathrm{5,} \mathrm{com} \mathrm{o} \mathrm{incremento} \mathrm{do} \mathrm{caráter} \mathrm{aniônico} \mathrm{pelo} \mathrm{compósito.} \mathrm{O} \mathrm{delineamento}$ experimental auxiliou na constatação de que a massa de $60 \mathrm{mg}$ de compósito e 30 minutos de tempo de contato é a melhor condição para aplicação, com 88,6\% de remoção de azul de metileno. Até 4 ppm de concentração do corante, o compósito apresentou eficiência superior a $80 \%$, e a partir de pH 5 a remoção do corante também é superior a $80 \%$, o máximo é observado em pH 11 com 95,6 \pm 0,2\%. A adsorção do corante pelo compósito teve bom ajuste ao modelo de Langmuir $\left(\mathrm{R}^{2}=\right.$ 0,9921), com $\mathrm{q}_{\max }$, igual a 109,9 $\mathrm{mg} \mathrm{g}^{-1}$ e $\mathrm{K}_{\mathrm{L}}$ equivalente a 2,19x10-2 $\mathrm{L} \mathrm{mg}^{-1}$. Portanto, o compósito desenvolvido nesse trabalho, sintetizado a partir da celulose oriunda dos resíduos de poda da Mangifera indica, foi eficaz na remoção do corante azul de metileno, apresentando-se como um material de baixo custo, pois foi obtido de um material que seria descartado, biodegradável e eficiente com potencial para ser aplicado no tratamento primário quimicamente assistido dos efluentes da indústria têxtil. Como sugestões para trabalhos futuros, estão a realização dos testes em amostras reais de lavanderias, a aplicação do compósito em amostras de chorume e na adsorção de metais pesados e o estabelecimento das condições para recuperação e reaplicação do compósito.

\section{Referências}

Agwuncha, S. C., Owonubi, S., Fapojuwo, D. P., Abdulkarim, A., Okonkwo, T. P., \& Makhatha, E. M. (2020). Evaluation of mercerization treatment conditions on extracted cellulose from shea nut shell using FTIR and thermogravimetric analysis. Materials Today: Proceedings, xxxx. https://doi.org/10.1016/j.matpr.2020.05.473

AL-Hammadi, S. A., Al-Absi, A. A., Bin-Dahman, O. A., \& Saleh, T. A. (2018). Poly(trimesoyl chloride-melamine) grafted on palygorskite for simultaneous ultra-trace removal of methylene blue and toxic metals. Journal of Environmental Management, 226 (August), 358-364. https://doi.org/10.1016/j.jenvman.2018.08.025

Alencar, W. S., Acayanka, E., Lima, E. C., Royer, B., de Souza, F. E., Lameira, J., \& Alves, C. N. (2012). Application of Mangifera indica (mango) seeds as a biosorbent for removal of Victazol Orange 3R dye from aqueous solution and study of the biosorption mechanism. Chemical Engineering Journal, 209, 577588. https://doi.org/10.1016/j.cej.2012.08.053

Alila, S., Besbes, I., Vilar, M. R., Mutjé, P., \& Boufi, S. (2013). Non-woody plants as raw materials for production of microfibrillated cellulose (MFC): A comparative study. Industrial Crops and Products, 41(1), 250-259. https://doi.org/10.1016/j.indcrop.2012.04.028

Ameen, F., Srinivasan, P., Selvankumar, T., Kamala-Kannan, S., Al Nadhari, S., Almansob, A., Dawoud, T., \& Govarthanan, M. (2019). Phytosynthesis of silver nanoparticles using Mangifera indica flower extract as bioreductant and their broad-spectrum antibacterial activity. Bioorganic Chemistry, 88(April), 102970. https://doi.org/10.1016/j.bioorg.2019.102970

Banat, F., Al-Asheh, S., Al-Ahmad, R., \& Bni-Khalid, F. (2007). Bench-scale and packed bed sorption of methylene blue using treated olive pomace and charcoal. Bioresource Technology, 98(16), 3017-3025. https://doi.org/10.1016/j.biortech.2006.10.023

Banerjee, S., Gautam, R. K., Jaiswal, A., Chattopadhyaya, M. C., \& Sharma, Y. C. (2015). Rapid scavenging of methylene blue dye from a liquid phase by adsorption on alumina nanoparticles. RSC Advances, 5(19), 14425-14440. https://doi.org/10.1039/c4ra12235f

Başaran Kankılıç, G., \& Metin, A. Ü. (2020). Phragmites australis as a new cellulose source: Extraction, characterization and adsorption of methylene blue. Journal of Molecular Liquids, 312. https://doi.org/10.1016/j.molliq.2020.113313

Beh, J. H., Lim, T. H., Lew, J. H., \& Lai, J. C. (2020). Cellulose nanofibril-based aerogel derived from sago pith waste and its application on methylene blue removal. International Journal of Biological Macromolecules, 160, 836-845. https://doi.org/10.1016/j.ijbiomac.2020.05.227

Bogolitsyn, K. G., Zubov, I. N., Gusakova, M. A., Chukhchin, D. G., \& Krasikova, A. A. (2015). Juniper wood structure under the microscope. Planta, 241(5), 1231-1239. https://doi.org/10.1007/s00425-015-2252-1

Bonetto, L. R., Crespo, J. S., Guégan, R., Esteves, V. I., \& Giovanela, M. (2021). Removal of methylene blue from aqueous solutions using a solid residue of the apple juice industry: Full factorial design, equilibrium, thermodynamics and kinetics aspects. Journal of Molecular Structure, 1224 , 129296. https://doi.org/10.1016/j.molstruc.2020.129296 
Cai, H., Du, F., Li, L., Li, B., Li, J., \& Shi, H. (2019). A practical approach based on FT-IR spectroscopy for identification of semi-synthetic and natural celluloses in microplastic investigation. Science of the Total Environment, 669, 692-701. https://doi.org/10.1016/j.scitotenv.2019.03.124

Chen, Q. J., Kang, M. C., Xie, Q. H., \& Wang, J. H. (2020). Effect of melamine modified cellulose nanocrystals on the performance of oil-immersed transformer insulation paper. Cellulose, 27(13), 7621-7636. https://doi.org/10.1007/s10570-020-03305-4

Choi, J., Fuentes, C., Fransson, J., Wahlgren, M., \& Nilsson, L. (2020). Separation and zeta-potential determination of proteins and their oligomers using electrical asymmetrical flow field-flow fractionation (EAF4). Journal of Chromatography A, 1633, 461625. https://doi.org/10.1016/j.chroma.2020.461625

Crothers, A. R., Li, C., \& Radke, C. J. (2021). A grahame triple-layer model unifies mica monovalent ion exchange, zeta potential, and surface forces. Advances in Colloid and Interface Science, 288(65), 102335. https://doi.org/10.1016/j.cis.2020.102335

Deeksha, B., Sadanand, V., Hariram, N., \& Rajulu, A. V. (2021). Preparation and properties of cellulose nanocomposite fabrics with in situ generated silver nanoparticles by bioreduction method. Journal of Bioresources and Bioproducts, 6(1), 75-81. https://doi.org/10.1016/j.jobab.2021.01.003

Dong, Y., Zhang, H., Zhong, G., Yao, G., \& Lai, B. (2021). Cellulose / carbon Composites and their Applications in Water Treatment - a Review. Chemical Engineering Journal, 405(August 2020). https://doi.org/10.1016/j.cej.2020.126980

El-Bouraie, M. (2015). Removal of the Malachite Green (MG) Dye From Textile Industrial Wastewater Using the Polyurethane Foam Functionalized with Salicylate. Journal of Dispersion Science and Technology, 36(9), 1228-1236. https://doi.org/10.1080/01932691.2014.964802

El-kott, A., Syef, A. F. A., Alshehri, M. A., Al Dessouky, S. I., \& Keshk, S. M. A. S. (2019). Suppression efficacy of lignosulfonate/mercerized cotton fiber composite against cancer cell's activities. Advanced Composites Letters, 28, 1-9. https://doi.org/10.1177/0963693519875974

Gómez-Carracedo, A., Alvarez-Lorenzo, C., Coca, R., Martínez-Pacheco, R., Concheiro, A., \& Gómez-Amoza, J. L. (2009). Fractal analysis of SEM images and mercury intrusion porosimetry data for the microstructural characterization of microcrystalline cellulose-based pellets. Acta Materialia, 57(1), 295-303. https://doi.org/10.1016/j.actamat.2008.09.009

Gupta, M. C., \& Iqbal, M. (2005). Ontogenetic histological changes in the wood of mango (Mangifera indica L. cv Deshi) exposed to coal-smoke pollution. Environmental and Experimental Botany, 54(3), 248-255. https://doi.org/10.1016/j.envexpbot.2004.09.003

Gurgel, L. V. A., Júnior, O. K., Gil, R. P. de F., \& Gil, L. F. (2008). Adsorption of Cu(II), Cd(II), and Pb(II) from aqueous single metal solutions by cellulose and mercerized cellulose chemically modified with succinic anhydride. Bioresource Technology, 99(8), 3077-3083. https://doi.org/10.1016/j.biortech.2007.05.072

Halasz, I., Agarwal, M., \& Miller, N. (2010). What can vibrational spectroscopy tell about the structure of dissolved sodium silicates? Microporus and Mesoporous Materials, 135, 74-81.

Han, S., Lyu, S., Chen, Z., Wang, S., \& Fu, F. (2019). Fabrication of melamine-urea-formaldehyde/paraffin microcapsules modified with cellulose nanocrystals via in situ polymerization. Journal of Materials Science, 54(9), 7383-7396. https://doi.org/10.1007/s10853-019-03352-8

Haque, A. N. M. A., Remadevi, R., Rojas, O. J., Wang, X., \& Naebe, M. (2020). Kinetics and equilibrium adsorption of methylene blue onto cotton gin trash bioadsorbents. Cellulose, 27(11), 6485-6504. https://doi.org/10.1007/s10570-020-03238-y

Hazarika, A., Deka, B. K., \& Maji, T. K. (2015). Melamine-formaldehyde acrylamide and gum polymer impregnated wood polymer nanocomposite. Journal of Bionic Engineering, 12(2), 304-315. https://doi.org/10.1016/S1672-6529(14)60123-2

Henriksson, M., \& Berglund, L. A. (2007). Structure and Properties of Cellulose Nanocomposite Films Containing Melamine Formaldehyde. Journal of Applied Polymer Science, 106, 2817-2824. https://doi.org/10.1002/app.26946

Ho, Y. S., Porter, J. F., \& Mckay, G. (2002). Equilibrium isotherm studies for the sorption of divalent metal ions onto peat: copper, nickel and lead single component systems. Water, Air, \& Soil Pollution, 141(1-4), 1-33.

Husson, E., Buchoux, S., Avondo, C., Cailleu, D., Djellab, K., Gosselin, I., Wattraint, O., \& Sarazin, C. (2011). Enzymatic hydrolysis of ionic liquidpretreated celluloses: Contribution of CP-MAS 13C NMR and SEM. Bioresource Technology, 102(15), 7335-7342. https://doi.org/10.1016/j.biortech.2011.04.097

Jawaid, S., Talpur, F. N., Afridi, H. I., Nizamani, S. M., Khaskheli, A. A., \& Naz, S. (2014). Quick determination of melamine in infant powder and liquid milk by Fourier transform infrared spectroscopy. Analytical Methods, 6(14), 5269-5273. https://doi.org/10.1039/c4ay00558a

Júnior, O. K., Gurgel, L. V. A., de Freitas, R. P., \& Gil, L. F. (2009). Adsorption of $\mathrm{Cu}(\mathrm{II})$, $\mathrm{Cd}(\mathrm{II})$, and $\mathrm{Pb}(\mathrm{II})$ from aqueous single metal solutions by mercerized cellulose and mercerized sugarcane bagasse chemically modified with EDTA dianhydride (EDTAD). Carbohydrate Polymers, 77(3), 643-650. https://doi.org/10.1016/j.carbpol.2009.02.016

Kabir, M. M., Wang, H., Lau, K. T., \& Cardona, F. (2012). Chemical treatments on plant-based natural fibre reinforced polymer composites: An overview. Composites Part B: Engineering, 43(7), 2883-2892. https://doi.org/10.1016/j.compositesb.2012.04.053

Kamble, Z., Behera, B. K., Mishra, R., \& Behera, P. K. (2021). Influence of cellulosic and non-cellulosic particle fillers on mechanical, dynamic mechanical, and thermogravimetric properties of waste cotton fibre reinforced green composites. Composites Part B: Engineering, 207(September 2020), 108595. https://doi.org/10.1016/j.compositesb.2020.108595

Kanemaru, T., Hirata, K., Takasu, S. I., Isobe, S. I., Mizuki, K., Mataka, S., \& Nakamura, K. I. (2010). A fluorescence scanning electron microscope. Materials Today, 12(SUPPL.), 18-23. https://doi.org/10.1016/S1369-7021(10)70141-3

Kapur, M., \& Mondal, M. K. (2013). Mass transfer and related phenomena for $\mathrm{Cr}(\mathrm{VI})$ adsorption from aqueous solutions onto Mangifera indica sawdust. Chemical Engineering Journal, 218, 138-146. https://doi.org/10.1016/j.cej.2012.12.054 
Keshk, S. M. A. S., \& Hamdy, M. S. (2019). Preparation and physicochemical characterization of zinc oxide/sodium cellulose composite for food packaging. Turkish Journal of Chemistry, 43(1), 94-105. https://doi.org/10.3906/kim-1803-83

Krishnamachari, P., Hashaikeh, R., \& Tiner, M. (2011). Modified cellulose morphologies and its composites; SEM and TEM analysis. Micron, 42(8), 751761. https://doi.org/10.1016/j.micron.2011.05.001

Kwiecińska, B., Pusz, S., \& Valentine, B. J. (2019). Application of electron microscopy TEM and SEM for analysis of coals, organic-rich shales and carbonaceous matter. International Journal of Coal Geology, 211(May), 103203. https://doi.org/10.1016/j.coal.2019.05.010

Laskar, I. B., Gupta, R., Chatterjee, S., Vanlalveni, C., \& Rokhum, L. (2020). Taming waste: Waste Mangifera indica peel as a sustainable catalyst for biodiesel production at room temperature. Renewable Energy, 161, 207-220. https://doi.org/10.1016/j.renene.2020.07.061

Li, Y., Cui, W., Liu, L., Zong, R., Yao, W., Liang, Y., \& Zhu, Y. (2016). Removal of Cr(VI) by 3D TiO2-graphene hydrogel via adsorption enriched with photocatalytic reduction. Applied Catalysis B: Environmental, 199, 412-423. https://doi.org/10.1016/j.apcatb.2016.06.053

Lutzke, A., Morey, K. J., Medford, J. I., \& Kipper, M. J. (2020). An FT-IR and XPS spectroscopy dataset of Pinus ponderosa sporopollenin and related samples to elucidate sporopollenin structural features. Data in Brief, 29(January), 105129. https://doi.org/10.1016/j.dib.2020.105129

Lyu, R., Zhang, C., Xia, T., Chen, S., Wang, Z., Luo, X., Wang, L., Wang, Y., Yu, J., \& Wang, C. W. (2020). Efficient adsorption of methylene blue by mesoporous silica prepared using sol-gel method employing hydroxyethyl cellulose as a template. Colloids and Surfaces A: Physicochemical and Engineering Aspects, 606(May), 125425. https://doi.org/10.1016/j.colsurfa.2020.125425

Marzouki, R., Brahmia, A., Bondock, S., Keshk, S. M. A. S., Zid, M. F., Al-Sehemi, A. G., Koschella, A., \& Heinze, T. (2019). Mercerization effect on structure and electrical properties of cellulose: Development of a novel fast Na-ionic conductor. Carbohydrate Polymers, 221(March), 29-36. https://doi.org/10.1016/j.carbpol.2019.05.083

Meira, A. M. (2010). Gestão de resíduos de arborização urbana. Escola Superior de Agricultura "Luiz de Queiroz."

Merline, D. J., Vukusic, S., \& Abdala, A. A. (2013). Melamine formaldehyde: Curing studies and reaction mechanism. Polymer Journal, 45(4), 413-419. https://doi.org/10.1038/pj.2012.162

Moghazy, R. M., Labena, A., \& Husien, S. (2019). Eco-friendly complementary biosorption process of methylene blue using micro-sized dried biosorbents of two macro-algal species (Ulva fasciata and Sargassum dentifolium): Full factorial design, equilibrium, and kinetic studies. International Journal of Biological Macromolecules, 134, 330-343. https://doi.org/10.1016/j.ijbiomac.2019.04.207

Nagarajan, D., Varada, O. M., \& Venkatanarasimhan, S. (2020). Carbon dots coated on amine functionalized cellulose sponge for the adsorption of the toxic herbicide atrazine. Materials Today: Proceedings, xxxx. https://doi.org/10.1016/j.matpr.2020.08.071

Pathania, D., Sharma, A., \& Srivastava, A. K. (2020). Modelling studies for remediation of Cr (VI) from wastewater by activated Mangifera indica bark. In Current Research in Green and Sustainable Chemistry (Vol. 3, Issue Vi). Elsevier B.V. https://doi.org/10.1016/j.crgsc.2020.100034

Pavan, F. A., Lima, E. C., Dias, S. L. P., \& Mazzocato, A. C. (2008). Methylene blue biosorption from aqueous solutions by yellow passion fruit waste. Journal of Hazardous Materials, 150(3), 703-712. https://doi.org/10.1016/j.jhazmat.2007.05.023

Poletto, M., Zattera, A. J., \& Santana, R. M. C. (2012). Thermal decomposition of wood: Kinetics and degradation mechanisms. Bioresource Technology, 126, 7-12. https://doi.org/10.1016/j.biortech.2012.08.133

Rehman, A., \& Park, S. J. (2018). Highlighting the relative effects of surface characteristics and porosity on CO2 capture by adsorbents templated from melamine-based polyaminals. Journal of Solid State Chemistry, 258(November 2017), 573-581. https://doi.org/10.1016/j.jssc.2017.11.019

Rizvi, S., Goswami, L., \& Gupta, S. K. (2020). A holistic approach for melanoidin removal via Fe-impregnated activated carbon prepared from Mangifera indica leaves biomass. Bioresource Technology Reports, 12(August), 100591. https://doi.org/10.1016/j.biteb.2020.100591

Sahiner, N., Demirci, S., \& Sel, K. (2016). Covalent organic framework based on melamine and dibromoalkanes for versatile use. Journal of Porous Materials, 23(4), 1025-1035. https://doi.org/10.1007/s10934-016-0160-9

Saleh, T. A., Sarı, A., \& Tuzen, M. (2017). Effective adsorption of antimony(III) from aqueous solutions by polyamide-graphene composite as a novel adsorbent. Chemical Engineering Journal, 307, 230-238. https://doi.org/10.1016/j.cej.2016.08.070

Seo, P. W., Khan, N. A., Hasan, Z., \& Jhung, S. H. (2016). Adsorptive Removal of Artificial Sweeteners from Water Using Metal-Organic Frameworks Functionalized with Urea or Melamine. ACS Applied Materials and Interfaces, 8(43), 29799-29807. https://doi.org/10.1021/acsami.6b11115

Sharifi, F., Jahangiri, M., Nazir, I., Asim, M. H., Ebrahimnejad, P., Hupfauf, A., Gust, R., \& Bernkop-Schnürch, A. (2021). Zeta potential changing nanoemulsions based on a simple zwitterion. Journal of Colloid and Interface Science, 585, 126-137. https://doi.org/10.1016/j.jcis.2020.11.054

Shen, L., Zhang, H., Lei, Y., Chen, Y., Liang, M., \& Zou, H. (2021). Hierarchical pore structure based on cellulose nanofiber/melamine composite foam with enhanced sound absorption performance. Carbohydrate Polymers, 255(October 2020), 117405. https://doi.org/10.1016/j.carbpol.2020.117405

Singh, B., Gupta, M., Verma, A., \& Tyagi, O. S. (2000). FT-IR microscopic studies on coupling agents: Treated natural fibres. Polymer International, 49(11), 1444-1451. https://doi.org/10.1002/1097-0126(200011)49:11<1444::AID-PI526>3.0.CO;2-9

Sreekala, M. S., \& Thomas, S. (2003). Effect of fibre surface modification on water-sorption characteristics of oil palm fibres. Composites Science and Technology, 63(6), 861-869. https://doi.org/10.1016/S0266-3538(02)00270-1

Tang, R., Dai, C., Li, C., Liu, W., Gao, S., \& Wang, C. (2017). Removal of Methylene Blue from Aqueous Solution Using Agricultural Residue Walnut Shell: Equilibrium, Kinetic, and Thermodynamic Studies. Journal of Chemistry, 2017. https://doi.org/10.1155/2017/8404965 
Research, Society and Development, v. 10, n. 6, e3710615331, 2021

(CC BY 4.0) | ISSN 2525-3409 | DOI: http://dx.doi.org/10.33448/rsd-v10i6.15331

Tsai, W. T., Yang, J. M., Lai, C. W., Cheng, Y. H., Lin, C. C., \& Yeh, C. W. (2006). Characterization and adsorption properties of eggshells and eggshell membrane. Bioresource Technology, 97(3), 488-493. https://doi.org/10.1016/j.biortech.2005.02.050

Ullah, S., Bustam, M. A., Ahmad, F., Nadeem, M., Naz, M. Y., Sagir, M., \& Shariff, A. M. (2015). Synthesis and characterization of melamine formaldehyde resins for decorative paper applications. Journal of the Chinese Chemical Society, 62(2), 182-190. https://doi.org/10.1002/jccs.201400226

Vieira, J. G., Filho, G. R., Meireles, C. D. S., Faria, F. A. C., Gomide, D. D., Pasquini, D., Cruz, S. F. D., De Assunção, R. M. N., \& Motta, L. A. D. C. (2012). Synthesis and characterization of methylcellulose from cellulose extracted from mango seeds for use as a mortar additive. Polimeros, 22(1), 80-87. https://doi.org/10.1590/S0104-14282012005000011

Wang, N., Chen, J., Wang, J., Feng, J., \& Yan, W. (2019). Removal of methylene blue by Polyaniline/TiO 2 hydrate: Adsorption kinetic, isotherm and mechanism studies. Powder Technology, 347, 93-102. https://doi.org/10.1016/j.powtec.2019.02.049

Xiong, Y., Tong, Q., Shan, W., Xing, Z., Wang, Y., Wen, S., \& Lou, Z. (2017). Arsenic transformation and adsorption by iron hydroxide/manganese dioxide doped straw activated carbon. Applied Surface Science, 416, 618-627. https://doi.org/10.1016/j.apsusc.2017.04.145

Yu, Y., Liu, S., Pei, Y., \& Luo, X. (2021). Growing Pd NPs on cellulose microspheres via in-situ reduction for catalytic decolorization of methylene blue. International Journal of Biological Macromolecules, 166, 1419-1428. https://doi.org/10.1016/j.jbbiomac.2020.11.021

Zeng, Q., Hao, T., Yuan, Z., \& Chen, G. (2020). Dewaterability enhancement and sul fi de mitigation of CEPT sludge by electrochemical pretreatment. Water Research, 176, 115727. https://doi.org/10.1016/j.watres.2020.115727

Zhang, H., \& Wang, X. (2009). Fabrication and performances of microencapsulated phase change materials based on n-octadecane core and resorcinolmodified melamine-formaldehyde shell. Colloids and Surfaces A: Physicochemical and Engineering Aspects, 332(2-3), 129-138. https://doi.org/10.1016/j.colsurfa.2008.09.013

Zhang, Q., Zhang, Z., Teng, J., Huang, H., Peng, Q., Jiao, T., Hou, L., \& Li, B. (2015). Highly efficient phosphate sequestration in aqueous solutions using nanomagnesium hydroxide modified polystyrene materials. Industrial and Engineering Chemistry Research, 54(11), 2940-2949. https://doi.org/10.1021/ie503943z

Zhang, Z., Zhu, M., \& Zhang, D. (2018). A Thermogravimetric study of the characteristics of pyrolysis of cellulose isolated from selected biomass. Applied Energy, 220(March), 87-93. https://doi.org/10.1016/j.apenergy.2018.03.057

Zhao, H., Kwak, J. H., Conrad Zhang, Z., Brown, H. M., Arey, B. W., \& Holladay, J. E. (2007). Studying cellulose fiber structure by SEM, XRD, NMR and acid hydrolysis. Carbohydrate Polymers, 68(2), 235-241. https://doi.org/10.1016/j.carbpol.2006.12.013

Zimmermann, T., Bordeanu, N., \& Strub, E. (2010). Properties of nanofibrillated cellulose from different raw materials and its reinforcement potential. Carbohydrate Polymers, 79(4), 1086-1093. https://doi.org/10.1016/j.carbpol.2009.10.045 